\title{
DESENVOLVIMENTO DE METODOLOGIA PARA A DETERMINAÇÃO DA VELOCIDADE ESPECÍFICA DE CRESCIMENTO DE EXPLANTES "in vitro"
}

\section{ANTONIO CARLOS RAMOS GONÇALVES}

Engenheiro agrônomo

Orientador: Prof. Dr. Antonio Natal Gonçalves

Dissertação apresentada à Escola superior de Agricultura "Luiz de Queiroz" Universidade de São Paulo, para a obtenção do título de Mestre em Ciências Florestais. Área de Concentração: Fisiologia da Árvore.

PIRACICABA

Estado de São Paulo - Brasil

Maio de 1998 


\section{Dados Internacionais de Catalogação na Publicação (CIP) DIVISÃo DE BIBLIOTECA E DOCUMENTAÇÃO - Campus "Luiz de Queiroz"/USP}

Gonçalves, Antonio Carlos Ramos

Desenvolvimento de metodologia para a determinação da velocidade especifica de. crescimento de explantes "in vitro" / Antonio Carlos Ramos Gonçalves. - - Piracicaba, 1999.

66 p. : il.

Dissertação (mestrado) - - Escola Superior de Agricultura Luiz de Queiroz, 1999.

Bibliografia.

1. Clone de eucalipto 2. Crescimento vegetal 3. Cultivo "in vitro" 4. Fisiologia vegetal I. Titulo

CDD 634.9734

"Permitida a copia total ou parcial deste documento, desde que citada a fonte . O Autor" 


\title{
AGRADECIMENTOS
}

\author{
À Christina Helena Rupp de Paiva Gonçalves, pela força. \\ Ao Prof. Dr. Antonio Natal Gonçalves, pela paciência. \\ À Carolina de Paiva Gonçalves e Julia de Paiva Gonçalves, pela alegria. \\ Ao Mestre Roberto Venceslau Carvalho, pela acolhida. \\ Ao Prof. Dr. Nilson B. Maia, pela amizade. \\ Ao Prof. Dr. Willibaldo Schidell Netto, pela crença.
}




\section{SUMÁRIO}

Página

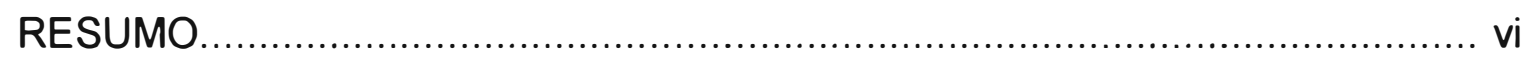

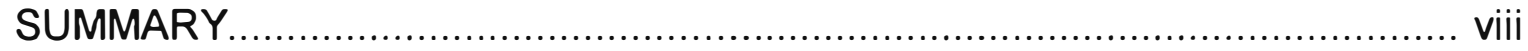

1. INTRODUÇÃO

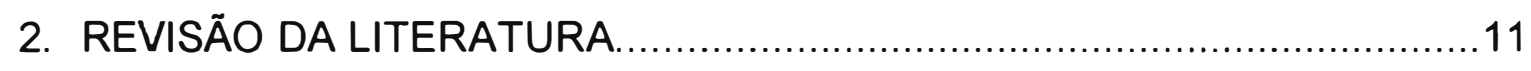

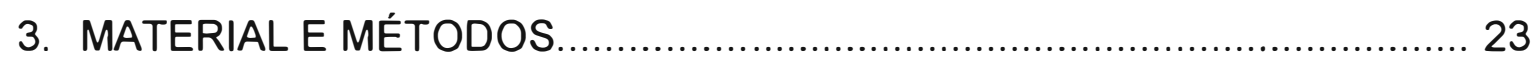

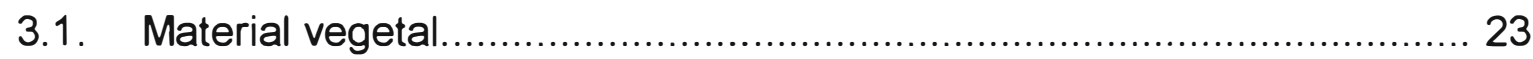

3.2. Condições ambientais de manutenção "in vitro" dos explantes.............. 24

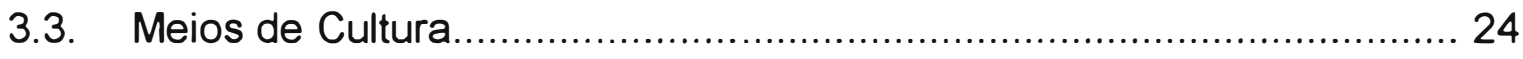

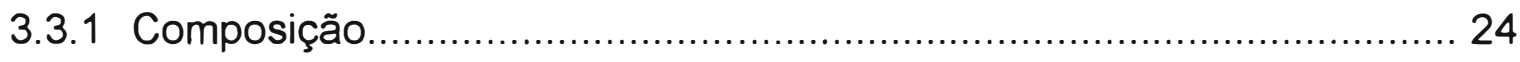

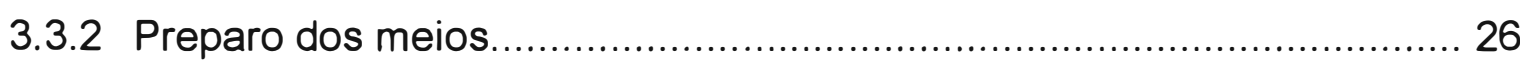

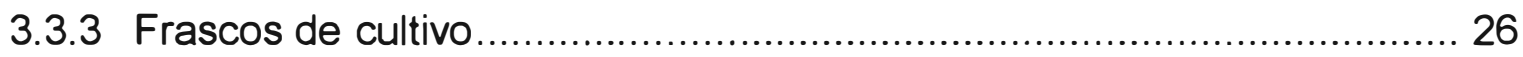

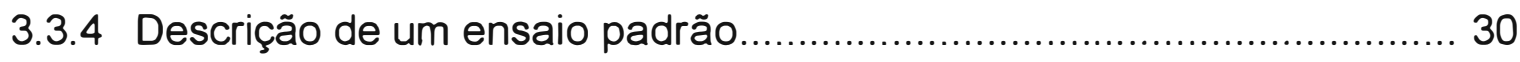

3.3.5 Ensaios de padronização dos explantes........................................... 34

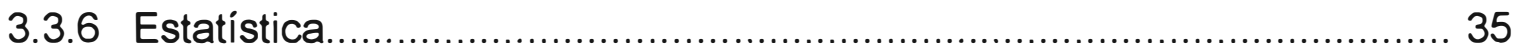

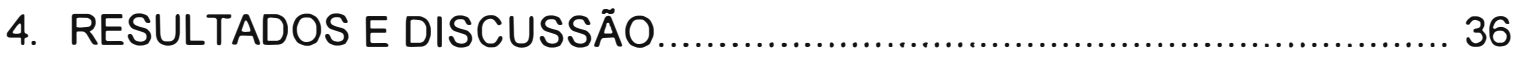

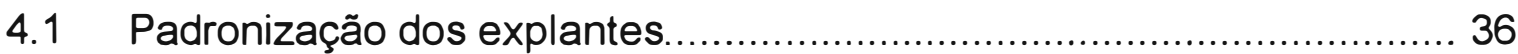

4.2 Correlação entre o peso da matéria fresca e o peso da matéria seca... 43

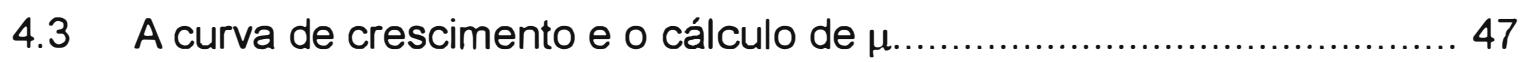

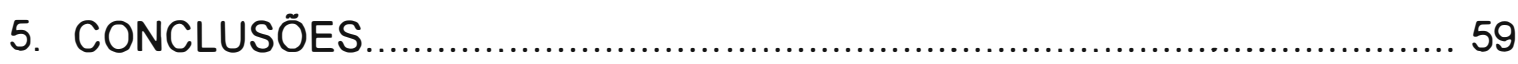

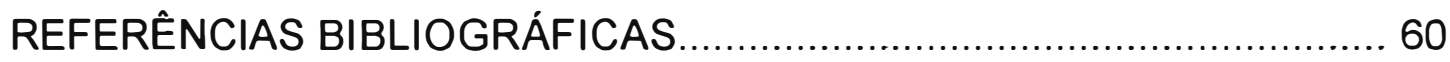




\section{DESENVOLVIMENTO dE METOdOLOGIA PARA A deTERMINAÇÃo dA VELOCIDAdE ESPECÍFICA DE CRESCIMENTO DE EXPLANTES “IN VITRO"}

Autor: ANTONIO CARLOS RAMOS GONÇALVES

Orientador: Prof. Dr. Antonio Natal Gonçalves

\section{RESUMO}

O objetivo deste trabalho de tese é o desenvolvimento de metodologia para a determinação da velocidade específica de crescimento de explantes, crescendo em meio de cultura líquido, a partir da experiência com o cultivo de microorganismos. O explante escolhido para a realização dos trabalhos experimentais foi obtido a partir do crescimento de nós epicórmicos de Eucalyptus híbrido. 
Baseados nos dados apresentados neste texto é possível concluir que o protocolo proposto para a padronização dos explantes mostrar-se adequado em relação a padronização do peso da matéria fresca dos explantes, obtendose como parâmetro de controle o coeficiente de variação de 4,18\% (CV\%).

Foi possivel determinar a existência de correlação entre o peso da matéria seca e o peso da matéria fresca. Matematicamente é possivel expressar essa correlação através da equação:

$$
\begin{aligned}
& \text { PMS = 0,125 + 0,0751 PMF, com } r=+0,9080, \quad \text { onde: } \\
& \text { PMS = Peso da Matéria Seca; } \\
& \text { PMF = Peso da Matéria Fresca; } \\
& r=\text { coeficiente de correlação. }
\end{aligned}
$$

Com a metodologia desenvolvida é possível, com ajustes inerentes a cada espécie estudada e com as repetições adequadas, determinar a velocidade específica de crescimento de explantes "in vitro". Para o caso específico de brotos epicórmicos de Eucalyptus híbrido foi possível calcular a velocidade específica de crescimento, obtendo-se o valor de $\mu=0,4547 \mathrm{dia}^{-1}$, correspondente a um tempo de duplicação de 36,59 horas. 


\title{
METHODOLOGY DEVELOPMENT FOR THE DETERMINATION OF THE ESPECIFIC GROWTH RATE OF PLANT EXPLANTS CULTURED “IN VITRO"
}

\author{
Author: ANTONIO CARLOS RAMOS GONÇALVES
}

Advisor: Prof. Dr. Antonio Natal Gonçalves

\section{SUMMARY}

The objective of this thesis is to develop a methodology to measure the specific growth rate of plant explants cultured in liquid media, using microorganisms culture knowledge as a starting point. For the experimental work, explants were obtained from the growth epicormic nodes of Eucalyptus hybrids.

From the data presented in this text it possible to conclude that the protocol designed to develop a standard pattern for explant size was adequate for standardization of the initial fresh weight of explants, with a coefficient of variation of $4.18 \%$. 
It was possible to determine a positive correlation between dry weight and fresh weight. This correlation can mathematically expressed in the equation:

$$
\begin{aligned}
& \text { DW }=0,125+0,0751 \mathrm{FW}, \quad \text { with } r=+0.9080, \text { where } \\
& \text { DW = Dry Weight; } \\
& \mathrm{FW}=\text { Fresh Weight; } \\
& \mathrm{R}=\text { correlation coefficient. }
\end{aligned}
$$

This methodology can be used to determine the specific growth rate of any plant species, as long as differences inherent to each species are considered and that adequate number of repetitions is used.

The application of this method allowed the determination of the specific growth rate of epicormic nodes of Eucalytus hybrid, which was $\mu=0.4547 /$ day, corresponding to a duplication time of 36.59 hours. 


\section{INTRODUÇÃO}

Quando, entre os anos de 1.861 e 1.863, o vigário José Honório da Silva plantou a primeira muda de eucalipto no Brasil, mais precisamente na Chácara da Cachoeira, nos arredores da cidade de São Paulo/SP, o fez, certamente, por razões estéticas. O eucalipto era plantado então por ser decorativo, também devido as suas possiveis qualidades terapêuticas, no entanto, já naquela época, uma outra qualidade da árvore também chamava atenção: a velocidade de crescimento (Andrade, 1939).

A velocidade parece ser o maior desafio a ser enfrentado pelo homem neste final de século. Tudo que é bom é rápido. O melhor deve ser sempre o mais rápido. O tempo passa a ser medido em décimos, centésimos, milésimos de segundos. É necessária muita acuidade nas medidas de velocidade, pois a excelência aparentemente está ligada à instantaneidade.

Se isto acontece sob o ponto de vista dos humanos, o mesmo parece não ser um paradigma para o restante da natureza. A evolução é lenta, contínua, mas implacável, esculpindo novos seres vivos a golpes de sorte em duplas fitas de DNA. Pobres humanos tentam conciliar seu desejo de velocidades crescentes e a pachorra da natureza aperfeiçoando a metodologia das medidas.

O homem tenta eleger, entre todos os seres vivos, aqueles que melhor se adaptem aos seus parâmetros de velocidade. No fundo o homem tenta de maneira desesperada moldar a história o mundo, com início, meio e fim, para que a mesma ocorra na fração de século em que vive.

A partir do momento em que se definiu pela primeira vez o conceito de velocidade: espaço percorrido em um intervalo de tempo, pode-se notar que 0 
mesmo sofisticou-se à medida que crescia sua importância para a sociedade. Hoje o conceito de velocidade é mais amplo, envolve a variação de uma grandeza qualquer em função do tempo. Qualquer segmento da sociedade tem lá sua velocidade de algo para usar como parâmetro de excelência.

Do ponto de vista botânico, a velocidade que interessa é a mesma que impressionou o Padre Honório, a velocidade de crescimento. Em se tratando de plantas, provavelmente seria melhor utilizar o conceito incremento no lugar de velocidade, pois na verdade, os vegetais ao crescerem sofrem incremento em sua massa. Como o conceito velocidade de crescimento está consagrado na botânica, o mesmo será amplamente utilizado nas discussões que se seguem neste texto.

O objetivo deste trabalho de dissertação de mestrado é o estabelecimento de uma metodologia para a determinação da velocidade específica de crescimento de explantes, tendo como base de trabalho a determinação da velocidade específica de crescimento de nós epicórmicos de Eucalyptus híbrido. 


\section{REVISÃO DE LITERATURA}

A velocidade de crescimento dos vegetais é um parâmetro determinante no estudo das plantas, inclusive nos aspectos evolutivos das mesmas (Grime, 1974, Grime, 1977). Por exemplo, a estratégia de crescimento está diretamente relacionada a velocidade de crescimento. Assim, árvores ditas pioneiras tem como estratégia o crescimento rápido, buscando atingir em curto espaço de tempo a luz do sol. Outras, mais características de floresta madura, tem a velocidade de crescimento mais ajustada à condições ambientais adversas podendo crescer poucos centímetros em vários anos, até que consiga, ao acaso, atingir o topo do dossel (Connell \& Slatyer, 1977; Janzen, 1980).

Essas variações na velocidade de crescimento tem sido objeto de vários estudos, e um procedimento normal para estes estudos é a elaboração de um modelo cinético.

Idealmente, os modelos cinéticos são tentativas de se descrever, através de equações matemáticas, o comportamento de seres vivos. Logo, sua validade é dependente de condições prévias muito rígidas, cuja inobservância das mesmas pode levar à erros grosseiros (Causton \& Venus, 1981).

Inúmeros modelos já foram propostos para descrever o crescimento de vegetais, e por conseqüência, a velocidade de crescimento de plantas. Uma ordem de grandeza do número de estudos encontrados na literatura pode ser obtida em Hunt (1982), em que o autor cita, baseado em dados do Biological Abstracts, 60.000 artigos científicos publicados sobre o tema somente na década de 70 . 
Um modelo é uma descrição de um conjunto de itens que permite encontrar ou definir alguma relação que seja objeto de estudo ou de interesse (Soares, 1992). Cada dada tentativa de criação de um modelo implica na definição de um sistema (escolha de um conjunto de objetos), e na determinação dos fatores externos (conjunto de objetos que podem afetar o sistema), muito embora estes últimos não sejam o foco do estudo. Se os fatores extemos forem de tal ordem que possam afetar seriamente o sistema, então três providências podem ser tomadas dependendo da situação em estudo:

- A definição do sistema pode ser estendida para englobar os fatores externos;

- Os fatores externos podem ser simplesmente ignorados;

- Os fatores externos podem ser tratados como entradas do sistema.

A escolha adequada do caminho a ser tomado irá determinar a qualidade do modelo proposto. Soares (1992) propõe que isto seja feito em duas etapas, numa primeira define-se o sistema, com uma precisa definição dos objetos a serem incluídos; e numa segunda etapa de refinamento define-se o modelo propriamente dito.

O refinamento de um modelo é uma função da utilização que se pretende dar ao mesmo, uma vez que cabe ao proponente do modelo definir quais os objetos que farão parte do mesmo e quais as inter-relações que se deseja obter (Gaudy Junior \& Gaudy, 1981).

A velocidade de crescimento das plantas é o resultado da interação de dois componentes: um genético, intrínseco a cada organismo; e um ambiental (Lawlor, 1991). O peso destas duas contribuições são semelhantes. O componente genético, também chamado de crescimento potencial, e o componente ambiental denominado como crescimento atual. O sistema no qual se pretende propor um modelo deverá considerar não só estas duas contribuições, como também uma terceira igualmente importante: o estágio de desenvolvimento do organismo sob estudo (Geps, 1987). 
Um princípio adequado para a proposição de um modelo é a utilização de um modelo anteriormente testado como ponto de partida, e daí proceder ao ajustes necessários para geração de um novo modelo (Soares,1992).

Que os microbiologistas, trabalhando com organismos unicelulares, acumulam uma notável experiência na elaboração de modelos cinéticos é fato conhecido á décadas (Dias, 1982). Porém a transposição dos modelos cinéticos desenvolvidos para microorganismos para organismos multicelulares é um problema complicado.

A questão básica é que no cultivo de organismos unicelulares enquanto houver substrato disponivel as células irão se dividir, aumentando a população, com cada indivíduo tendo um comportamento semelhante àquele de seu vizinho. Já com os vegetais em geral, e as árvores em particular, as interações entre indivíduos dentro de uma população tem uma importância muito maior do que o comportamento de um indivíduo propriamente dito. As interações com o nicho ecológico ocupado, a estratégia de reprodução e a competição por nutrientes, e as relações com predadores (herbivoria) tem um significado maior do que a velocidade de crescimento em si (Trewavas \& Allan, 1987).

Ao se tentar simular matematicamente o crescimento de uma planta, os fatores acima citados acabam tendo um peso superior ao crescimento do individual. Alguns autores chegam a afirmar, que a competição entre os indivíduos é o fator básico para o crescimento das plantas. A competição por recursos escassos é tão fundamental para a existência das plantas que chega-se ao extremo de existir competição entre os órgãos e células de um mesmo vegetal por nutrientes (Grime, 1974; Grime, 1977; Trewavas \& Allan, 1987).

A distribuição desigual dos 17 elementos químicos necessários ao crescimento das plantas é a principal razão para a especiação das angiospermas, segundo Trewavas e Allan (1987).

Mesmo que fosse razoável utilizar o crescimento de uma única planta para as medidas de velocidade de crescimento, apareceriam outras ordens de 
problemas. Taiz \& Zeiger (1991) afirmaram que células vegetais em suspensão, em termos de plantas, é o que pode ser considerado mais próximo de uma cultura de organismos unicelulares, tem o incremento de sua massa basicamente devido ao aumento do número de células. Porém, mesmo neste caso ocorrem variações importantes devido à diferentes estados de hidratação das mesmas. Aqui detalhes anatômicos, como a existência de um vacúolo grande funcionando, entre outras coisas, como regulador de pressão osmótica das células, são determinantes para estas variações (Fahn, 1982).

As plantas são muito mais do que simplesmente um conjunto de células coladas umas as outras. Isto acarreta grandes implicações. Organizados em tecidos diferenciados os vegetais podem ter comportamento desconcertante. Nos estágios iniciais de crescimento de embriões zigóticos existem momentos em que ocorre aumento do número de células sem o correspondente incremento de massa do embrião. As "células filhas" são menores do que aquelas que a geraram (Taiz \& Zeiger, 1991).

A organização dos seres vivos em tecidos obedece uma certa ordem préestabelecida (genética). Todas as células de um organismo são oriundas de uma única célula inicial, o zigoto, e através de diferenciações dão origem aos vários tecidos que irão compor o indivíduo adulto. Isto é um complicador a mais nas medidas de velocidade de crescimento, pois diferentemente dos processos de dupla etapa, crescimento e divisão celular, que ocorrem em cultivo de organismos unicelulares, aqui mais uma etapa deverá ser considerada no processo: o aparecimento de tecidos especializados (Fahn, 1982).

Além disto, nos vegetais o crescimento ocorre em regiões bem determinadas, os meristemas (tecidos localizados basicamente nos ápices das plantas, e são os responsáveis pelo crescimento primário (Margara, 1988). Então a velocidade de crescimento de plantas seria muito próxima a velocidade de diferenciação dos meristemas. Como o crescimento é feito as custas de nutrientes absorvidos pelas raizes (mais os açúcares sintetizados pelas folhas) e translocados 
até os meristemas, fica claro a correlação proposta por Ingestad \& Ågren (1992) de que a velocidade de crescimento é diretamente proporcional a velocidade de absorção dos nutrientes.

Nas plantas, em determinados momentos, a velocidade de crescimento pode ainda ser afetada pelo estado fisiológico, através de mudanças na relação fonte/dreno. Os frutos são um dreno preferencial às demais partes da planta, e quando ocorre o florescimento e a frutificação, o crescimento em algumas plantas, especialmente cereais, praticamente cessa (Castro, 1989).

No entanto, o crescimento dos seres vivos, muito embora seja um processo complexo, quando medido continuamente em relação ao tempo resulta em uma curva característica, na forma de "S", conhecida como curva de crescimento (Taiz \& Zeiger, 1991). É baseado nesta característica comum que pode-se propor modelos cinéticos de crescimento de organismos (Dias, 1982).

Basicamente, uma curva de crescimento pode ser dividida em quatro etapas distintas: uma fase inicial, chamada de "fase lag", caracterizada por um crescimento muito discreto, como se houvesse uma preparação do sistema enzimático para a fase seguinte.

Segue-se uma fase de crescimento expressivo, quando a velocidade de crescimento fica constante, e máxima para as condições ambientais estudadas, chamada de "fase log" devido ao ajuste logaritmo do crescimento nesta etapa. Posteriormente, ocorre uma fase estacionária, quando a velocidade de crescimento cai de forma significativa, reduzindo-se o crescimento à reposição das células e tecidos perdidos, mantendo o tamanho da população, ou do indivíduo no caso de organismos multicelulares, constante.

Finalmente, aparece uma fase de declínio, em que há perda de material celular, levando a diminuição do tamanho da população quando confrontado com o tempo (Gaudy Junior \& Gaudy, 1981; Dias, 1982; Taiz \& Zeiger, 1991)

A partir do estabelecimento da curva de crescimento, em que $X$ (massa de células ou tecidos) é uma função do tempo, $X=X(t)$ é possivel se obter a 
velocidade de crescimento, derivando esta função em relação ao tempo, desde que se tenha tomado os cuidados necessários com a validade do mesmo.

Apesar da quantidade de conhecimentos obtidos no estudo de microorganismos ainda existem problemas. Analisando o comportamento de leveduras cultivadas em meio de cultura de melaço, Dias (1982), afirmou que "o tempo de duplicação de $X$ e a velocidade específica de crescimento variam com uma série de fatores entre os quais se incluem: temperatura, $\mathrm{pH}$, concentração de nutrientes, inibidores e estado de agitação da cultura".

Para plantas, é de se esperar que mais fatores, além destes influenciem a velocidade de crescimento. Uma forma de contornar em parte o problema é adotar a cultura "in vitro" e escolher uma determinada fase de desenvolvimento da planta para se trabalhar na coleta das medidas de velocidade, como procedeu Correia (1993).

A escolha da fase de desenvolvimento da planta fica, em parte limitada pela técnica da cultura "in vitro". Ainda assim, não é uma escolha fácil, pois o número de fases de uma planta pode variar, dependendo do autor citado, ou de uma dada planta estudada. Enquanto que o CIAT reconhece, por exemplo, que o feijão comum tem somente uma fase de crescimento e outra de reprodução, Nuland et al. (1983) ${ }^{1}$ citado por Geps (1987) propuseram que sejam consideradas quatro fases para a mesma planta: germinação e estabelecimento da plântula; rápido crescimento vegetativo; florescimento e formação das vagens; e enchimento das vagens e maturação.

A escolha de uma fase determinada do desenvolvimento das plantas para a realização das medidas de velocidade em particular, e outras medidas fisiológicas em geral, foi utilizada por Ingestad \& Âgren (1992); Ingestad (1978); Ingestad

1 NULAND, D. S.; SCHAWARTZ, H. F.; FORSTER, R. L. Recognition and Management of Dry Bean Production Problems, North Central Regional Publ., 1993. 
(1970) e Ingestad (1971), estudando plântulas de bétula (Betula verrucosa Ehrh.); Hangarter \& Stasinopoulus (1991), com raizes de Arabidopsis thaliana; Bagni et al. (1971), usando segmentos de tubérculos de Helianthus tuberosus; Mezzetti et al. (1991), estudando o comportamento de calos, segmento de caule e folhas de Actinidia deliciosa; e Alvard et al. (1993) cultivando brotos de bananeira, Musa acuminata, cv. Grand Naine; Correia (1993) que utilizou em estudos anteriores de velocidade de crescimento, em meio bifásico, gemas de eucalipto.

Uma das dificuldades de se medir a velocidade de crescimento de plantas, e em especial de árvores, é a necessidade de trabalhar com ensaios destrutivos. A curva de crescimento, que dará origem aos cálculos de velocidade é do tipo $X=X$ $(t)$, ou seja massa, ou uma outra medida de tamanho, em função do tempo. Como as plantas são enraizadas é necessário que se destrua o ensaio para que se possa medir a massa ou o tamanho (Taiz \& Zeiger, 1991).

Uma das formas de se contornar este problema é a utilização da velocidade específica de crescimento " $\mu$ ". Proposta inicialmente por Blackman $(1919)^{2}$, citado por South (1991), é definido como:

$$
\mu=1 / X(d X / d t)
$$

(Equação 1)

Ou seja, a velocidade específica de crescimento $(\mu)$ é igual à massa de células produzidas na unidade de tempo, por unidade de massa. Quando a velocidade específica de crescimento se mantêm constante, a Equação 1 acima pode ser integrada entre os limites $t_{1}, X_{1}$ e $t_{2}, X_{2}$ resultando na função matemática que é a base do crescimento exponencial (Dias, 1982):

$$
X_{2}=X_{1} \exp \left[\mu\left(t_{2}-t_{1}\right)\right] \quad \text { (Equação 2) }
$$

Esta equação tem sido muito utilizada para o cálculo da velocidade específica de crescimento celular de microorganismos, cultivados em regime

2 BLACKMAN, V.H. The compound interest law and plant growth. Annals of Botany, v. 33, p. 353-360, 1919. 
descontínuo. O valores experimentais são lançados em um gráfico mono-logarítmo, e determinando-se o valor de $\mu$ como sendo numericamente igual a tangente à reta obtida.

Considera-se, quando do cálculo de $\mu$, que as condições ambientais são ótimas, então, nestas condições pode-se afirmar que esta velocidade é a total expressão do potencial genético da espécie.

Mas como muito bem definiu Lawlor (1991), a existência do componente ambiental implica que a expressão máxima do genoma será um valor, quando muito, igual ao crescimento potencial, pois o ambiente sempre tenderá a causar algum atraso no suprimento dos nutrientes necessários para que as reações químicas de um organismo se processem na sua velocidade máxima possível.

Assim, deve-se trabalhar com um modelo que considere a questão nutricional na proposição do mesmo, e dentre os vários modelos cinéticos de crescimentos propostos destaca-se o modelo de Monod, utilizado principalmente para descrever a velocidade de crescimento de microorganismos em função de um substrato limitante (Gaudy Junior \& Gaudy, 1981), ou seja:

$$
\begin{aligned}
& \mu=\mu_{\max } \mathrm{S}_{0} /\left(\mathrm{K}_{\mathrm{s}}+\mathrm{S}_{0}\right), \text { em que, } \\
& \mu=\text { velocidade de crescimento; } \\
& \mu_{\max }=\text { velocidade máxima de crescimento; } \\
& \mathrm{K}_{\mathrm{s}}=\text { constante de saturação; } \\
& \mathrm{S}_{0}=\text { concentração do substrato limitante. }
\end{aligned}
$$

A aparente incongruência entre a afirmação de que $\mu$ é constante na fase logarítmica de crescimento, e um modelo que considera a velocidade de crescimento como uma função da concentração de um determinado substrato limitante $\left(S_{0}\right)$, é explicada Borzani (1975): os valores de $S_{0}$ são muito superiores aos valores de $K_{s}$, fazendo $\mu=\mu_{\max }$.

$O$ ajuste dos dados experimentais à equação de Monod tem como implicação que a velocidade de crescimento varia somente com a concentração de um substrato limitante, sem interferência no sistema, por exemplo, de substâncias 
inibidoras.

Crescendo em meio de cultivo determinado, com todos os seus componentes conhecidos, abre-se a possibilidade, baseado em teoria proposta por Ingestad (1971) e Ingestad \& Âgren (1992), de avanços significativos no entendimento da nutrição e crescimento dos vegetais.

Esta teoria baseia-se em dois conceitos fundamentais. O primeiro deles é que os nutrientes minerais fluem para dentro das plantas de modo que sua concentração interna permaneça constante. Os autores demonstraram, baseados em experimentos com espécies e condições ambientais diversas, que a taxa de absorção dos nutrientes $\mathbf{R u}$, é igual a taxa de crescimento do vegetal $\mathbf{R g}$. O segundo conceito é que a taxa de crescimento $\mathbf{R g}$ observa uma correlação linear com a concentração interna do nutriente analisado, $\mathbf{n} \mathbf{W}$ (em que, $n=$ concentração de dado nutriente; e W = biomassa da planta) Ingestad (1971) e Ingestad \& Ågren (1992). A partir desta elaboração teórica, os autores concluíram que o coeficiente angular entre $\mathbf{R g}$ e $\mathbf{n} \mathbf{W}$ fornece o parâmetro $\mathbf{P}_{\mathbf{n}}$, ou seja a produtividade da planta.

Tendo como base os conceitos acima, Correia (1993) realizou experimentos com Eucalyptus grandis, e alguns de seus híbridos, visando avaliar o desenvolvimento de gemas em função do tempo e de variações do meio de cultura.

Resultados expressivos, no que se refere ao crescimento, foram obtidos com uma adição semanal de meio líquido fresco sobre o material em crescimento. Acréscimos de até $112,7 \%$ no número de brotações foram obtidos nos tratamentos onde houve suplementação com meio de cultura novo, indicando ser possivel obter ganho nas fases iniciais de cultura "in vitro" se for mantido algo próximo ao "steadystate" preconizado por Ingestad (1971) e Ingestad \& Ågren (1992).

Agora é necessário abordar alguns tópicos relativos a técnica de cultivo a ser utilizada. A micropropagação de eucaliptos é uma técnica relativamente nova. Os primeiros calos foram obtidos em 1965 utilizando-se como material de explante "seedlings" de E. camaldurensis. As primeiras plantas foram regeneradas de "callus" de caule de E. citriodora, em 1969 (Ouyang \& Peng, 1990). Esta técnica 
tem sido indicada como de grande impacto na silvicultura, pois possibilita a propagação de genótipos desejáveis sem perda da matriz; obtenção de altas taxas de multiplicação com reversão a juvenilidade; redução do tempo para obter-se e avaliar-se, os clones; e a ampliação das opções das estratégias de melhoramento genético (Gonçalves, 1982).

Existe a estimativa de que hoje no Brasil, considerável fração da celulose produzida é oriunda de material clonado, muito embora a clonagem se dê preferencialmente através do enraizamento de estacas. Algumas empresas chegam a basear sua produção, em percentuais de até $95 \%$, na propagação vegetativa (Bertolucci \& Penchel, 1993). Além da propagação em si, a cultura "in vitro" pode se poderosa ferramenta na reversão da juvenilidade, barreira para a produção de clones por estaquia em algumas espécies e muito híbridos (Gonçalves, 1975; Gonçalves, 1982).

A micropropagação de eucaliptos visando a produção de mudas clonadas, técnica que nos últimos anos se desenvolveu admiravelmente, é um assunto bem conhecido, sendo que hoje não apresenta grandes problemas. Vários tipos de explantes e diferentes meios de cultura são utilizados, como demonstra a revisão de bibliografia feita por Correia (1993).

A cultura "in vitro" pressupõe a utilização de um meio de cultura como fonte de nutrientes para os explantes. A necessidade de fornecimento de oxigênio, e muitas vezes o segmento ou órgão usado como explante não sendo especializado na captação deste nutriente fez com que, historicamente, a cultura de tecido fosse realizada com a máxima exposição do material vegetal ao ar. Isto foi conseguido pela utilização de meios sólidos ou semi-sólidos, ou então com a utilização de suportes quando o meio é líquido. (Caldas et al., 1990).

Os meios de cultivo sólidos, principalmente os que utilizam agar como agente geleificante, tem como conseqüência dificultar a absorção dos nutrientes 
pelo explante quando comparados com os meios líquidos. Heller et al. (1968) ${ }^{3}$ citado por Caldas et. al. (1990), determinou que a absorção de fosfato por explantes de cenoura em meio líquido foi mais rápida do que em meio sólido, muito embora houvesse uma maior absorção de água. Os explantes de cenoura em meio líquido tinham $50 \%$ mais água por grama de matéria seca do que os explantes crescidos em meio sólido.

Se já existe um componente ambiental que reduz a transferência de nutrientes para dentro da planta, de modo que Ingestad \& Ågren (1992) propõe que a velocidade de crescimento seja igual a velocidade de absorção, então não há sentido em se utilizar um meio de cultura que crie mais um obstáculo para a transferência dos nutrientes para dentro dos tecidos das plantas. Tal pensamento é compartilhado por Debergh (1995), quando este aponta a necessidade da utilização de meios de propagação com menores concentrações de agar, ou mesmo a utilização de meio líquido, como uma forma de incrementar a eficiência dos esquemas de micropropagação em geral.

Meios de cultivo líquido podem, potencialmente, apresentar problemas como a hiperhidricidade, ou vitrificação, quando se trata de plantas herbáceas e lenhosas. São várias as causas que podem levar a este tipo de problema, e uma delas é a absorção excessiva de água por parte dos explantes, devido a alta disponibilidade de água. A adoção de meios de cultura sólidos, ou mesmo aumento do teor do agente geleificante, corrigiu o problema da vitrificação (Gaspar et al., 1982).

Recentemente, surgiu uma forma de conciliar as vantagens de trabalhar com meio de cultura líquido, sem contudo ter problemas com a hiperhidricidade, ou

${ }^{3}$ HeLLER, R.; DARPAS, A.; DEVILLERS, P.; RICHEZ, M. Absorption et exsorption des tissus et fragments vegetaux en culture. In: Les cultures de tissus de plantes. Paris, CNRS, 1968, p.149-169. 
mesmo o falta de suprimento de oxigênio para os explantes.

Os autores desta técnica a denominaram de "cultura sob imersão temporária" (Teisson \& Alvard, 1994), a qual mostrou resultados satisfatórios com as culturas de Citrus, Coffea, Elaeis, Hevea e Musa. Neste sistema, os explantes ficam totalmente submersos por intervalos variando entre 1 e 20 minutos, e uma freqüência de 2 a 6 vezes cada período de 24 horas.

Nos ensaios de Teisson \& Alvard (1994), os parâmetros físicos dentro do frasco de cultura puderam ser medidos sob as condições de quatro imersões de 1 minuto, distribuídas regularmente durante cada período de 24 horas. Assim, durante a fase escura, a atmosfera ficou saturada de vapor d'água, com este valor caindo para $98 \%$ de umidade relativa durante a fase iluminada (Teisson \& Alvard, 1994).

Esta técnica de cultivo apresentou vantagens quando comparado ao cultivo em meio líquido estacionário; meio líquido com a utilização de "pontes de celulose"; meio líquido com imersão parcial do explante; meio líquido aerado. Explantes submetidos ao cultivo sob imersão temporária apresentaram, para o parâmetro acúmulo de matéria seca, valores 2 a 5 vezes maiores do que o tratamento que teve o segundo melhor desempenho (Alvard et al., 1993).

O sistema de cultivo sob imersão temporária foi utilizado para o cultivo de embriões somáticos de várias cultivares banana com a obtenção de uma excelente taxa de propagação. Foi possível a obtenção de 6.000 embriões somáticos em apenas 6 meses de sub-cultura ( 1 minuto de imersão a cada 6 horas) (Escalant et al., 1994). 


\section{MATERIAL E MÉTODOS}

Os ensaios foram realizados no Laboratório da Multiplica Tecnologia Vegetal Ltda. localizado no município de Salto de Pirapora, Estado de São Paulo. As determinações físicas foram feitas no Laboratório de Fisiologia das Árvores do Departamento de Ciências Florestais da Escola Superior de Agricultura "Luiz de Queiroz". Os procedimentos experimentais foram realizados no período compreendido entre junho e dezembro de 1997.

\subsection{Material Vegetal}

O material utilizado para a realização dos experimentos foram brotos epicórmicos de eucalipto híbrido. Os explantes foram obtidos originalmente por Correia (1993), a partir de árvores híbridas de Eucalyptus grandis x Eucalyptus urophylla, cruzamento 07.148.019, denominado clone "H10", cedido pela empresa Chamflora Agrícola Ltda., para trabalhos de pesquisa no Departamento de Ciências Florestais da ESALQ-USP.

As informações taxonômicas da árvore matriz, fornecidas pelo Departamento de Genética Florestal da Chamflora Agrícola Ltda., estão descritas em Correia (1993).

A Figura 1 (página 25) mostra, em detalhes, o explante típico de eucalipto utilizado neste trabalho. Pode-se notar que os nós epicórmicos são presos pela base formando um tufo de brotações. Esta forma acarreta diferente retenção de 
água para cada explante considerado, o que demanda procedimentos específicos para as medidas de massa que foram efetuadas.

\subsection{Condições Ambientais de Manutenção "in vitro" dos Explantes}

Os explantes foram mantidos em cultura, desde 1991, em meio JADS, descrito por Correia (1993), sólido, no Laboratório de Fisiologia da Árvore e Micropropagação do Departamento de Ciências Florestais da Escola Superior de Agricultura "Luiz de Queiroz", e depois no Laboratório da Multiplica Tecnologia Vegetal Ltda.

$\mathrm{Na}$ ESALQ, as culturas permaneceram em condições ambientais para o crescimento à temperatura de $26 \pm 2{ }^{\circ} \mathrm{C}$, fotoperíodo de 16 horas e luminosidade equivalente a 1.000 LUX. Já, no Laboratório da Multiplica, as condições ambientais foram levemente alteradas para $28 \pm 4{ }^{\circ} \mathrm{C}$, fotoperíodo de 16 horas e luminosidade equivalente a 2.000 LUX.

\subsection{Meios de Culturas}

\section{a. Composição}

Durante a realização dos ensaios, foram utilizados os meios de cultura JADS, na forma líquida e sólida, e "A3". O meio JADS foi desenvolvido por um grupo de pesquisadores para o cultivo de eucalipto (Correia, 1993).

A tabela 1., da página 27, apresenta a composição do meio de cultura JADS, enquanto que a tabela 2., da página 28 , apresenta a composição do meio de cultura "A3". Em ambos os meios de cultura o pH foi ajustado para o valor de 6,0 \pm 0,1 com o auxílio de ácido clorídrico $1 \mathrm{~N}$, ou hidróxido de potássio $1 \mathrm{~N}$, antes da esterilização em autoclave. 


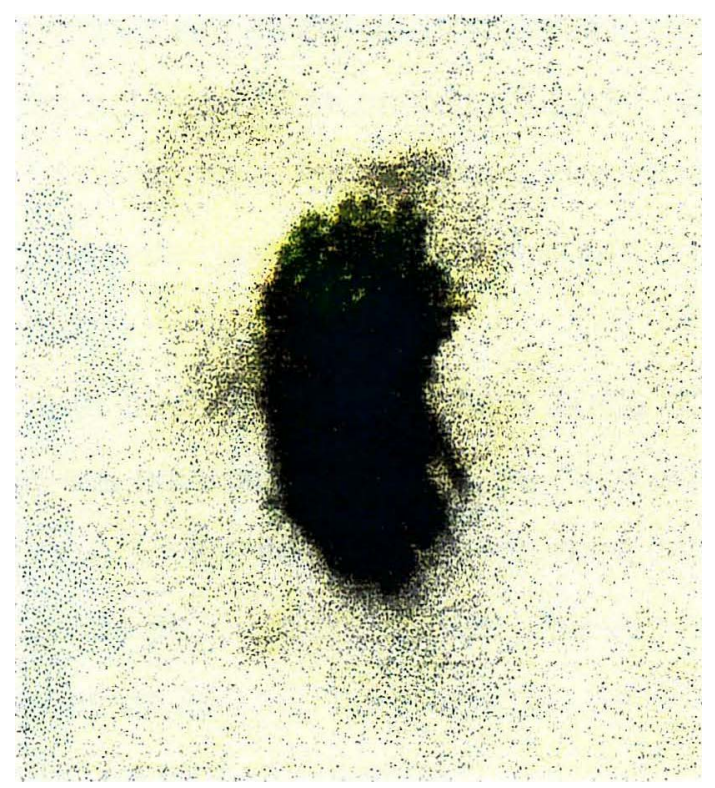

Figura 1. Explante padrão : nó epicórmico de eucalipto. 


\section{b. Preparo dos meios}

Soluções estoque dos sais nutrientes do meio JADS foram preparadas, prevendo-se diluição adequada segundo mostra a Tabela 3., da página 28 , e armazenadas em geladeira (temperatura entre 4 e $8^{\circ} \mathrm{C}$ ). As vitaminas, aminoácidos e o promotor de crescimento (6-BAP), em concentração adequada para o preparo de 1 litro de meio, foram congelados em forma de cubos de gelo. No momento do uso, o cubo de gelo era vertido em uma proveta de um litro, facilitando assim o procedimento.

Quando se trata de meio sólido, após o ajuste do pH e da adição do agente geleificante, o meio era aquecido em forno de microondas, potência máxima (330 watts) por um período equivalente a 10 minutos para cada litro de meio em preparo.

Findo o aquecimento, o meio era mais uma vez homogeneizado e então, era dispensado em frascos de $250 \mathrm{~mL}$, na proporção de $50 \mathrm{~mL}$ de meio por frasco, que logo após era fechado de forma hermética.

Todos os tipos de meio, independente de seu estado físico, foram esterilizados em autoclave sob as seguintes condições: temperatura, $121{ }^{\circ} \mathrm{C}$; pressão de $1,05 \mathrm{kgf} / \mathrm{cm}^{2}$; e tempo de 15 minutos.

\section{c. Frascos de Cultivo}

A multiplicação dos explantes e a sua adaptação antes dos ensaios foram feitas em frascos de $250 \mathrm{~mL}$ de volume e tampa plástica. Estas garantem a esterilidade do ambiente interno, muito embora não permitam nenhuma troca de gases entre o ambiente e o meio de cultivo.

Os ensaios destrutivos para o levantamento dos pontos da curva de crescimento foram realizados em frascos especiais, doravante denominados "aparatos", ou simplesmente "AP", que podem ser visualizados na Figura 2., da página 29 , e cuja descrição segue na página 28. 
Tabela 1. Composição do meio de cultura JADS (Correia, 1993).

\begin{tabular}{|c|c|}
\hline Substância & Concentração (mg/l) \\
\hline $\mathrm{NH}_{4} \mathrm{NO}_{3}$ & 324,0 \\
\hline $\mathrm{KNO}_{3}$ & 809,0 \\
\hline $\mathrm{KH}_{2} \mathrm{PO}_{4}$ & 408,0 \\
\hline $\mathrm{Ca}\left(\mathrm{NO}_{3}\right)_{2} \cdot 4 \mathrm{H}_{2} \mathrm{O}$ & $1.181,0$ \\
\hline $\mathrm{Mg} \mathrm{SO}_{4} \cdot 7 \mathrm{H}_{2} \mathrm{O}$ & 739,5 \\
\hline $\mathrm{Fe} \mathrm{SO}_{4} \cdot 7 \mathrm{H}_{2} \mathrm{O}$ & 55,6 \\
\hline $\mathrm{Na}_{2} \cdot \mathrm{EDTA}$ & 74,5 \\
\hline $\mathrm{Na}_{2} \mathrm{MoO}_{4} \cdot 2 \mathrm{H}_{2} \mathrm{O}$ & 0,15 \\
\hline $\mathrm{MnSO}_{4} \cdot \mathrm{H}_{2} \mathrm{O}$ & 16,9 \\
\hline $\mathrm{ZnSO}_{4} \cdot 7 \mathrm{H}_{2} \mathrm{O}$ & 4,32 \\
\hline $\mathrm{CuSO}_{4} \cdot 5 \mathrm{H}_{2} \mathrm{O}$ & 1,25 \\
\hline $\mathrm{CoCl}_{2} \cdot \mathrm{H}_{2} \mathrm{O}$ & 0,25 \\
\hline $\mathrm{H}_{3} \mathrm{BO}_{3}$ & 3,1 \\
\hline Ácido Nicotínico & 0,5 \\
\hline Pirodoxina $\mathrm{HCl}$ & 0,5 \\
\hline Tiamina $\mathrm{HCl}$ & 5,0 \\
\hline m Inositol & 100,0 \\
\hline L-Arginina & 7,0 \\
\hline L-Glutamina & 146,0 \\
\hline L-Cisteína & 2,5 \\
\hline Pantotenato de Cálcio & 2,4 \\
\hline Sacarose & $30.000,0$ \\
\hline Agar* & $6.000,0$ \\
\hline 6-BAP & 0,5 \\
\hline
\end{tabular}

* = Somente utilizado para a elaboraçāo de meio sólido. 
Tabela 2. Composição do meio de cultura "A3".

\begin{tabular}{lc}
\hline Substância & Concentração (g/l) \\
\hline Açúcar (sacarose) & 15,0 \\
\hline Agar & $\mathbf{4 , 0}$ \\
\hline
\end{tabular}

Tabela 3: Fatores de diluição das soluções estoque de nutrientes do meio JADS.

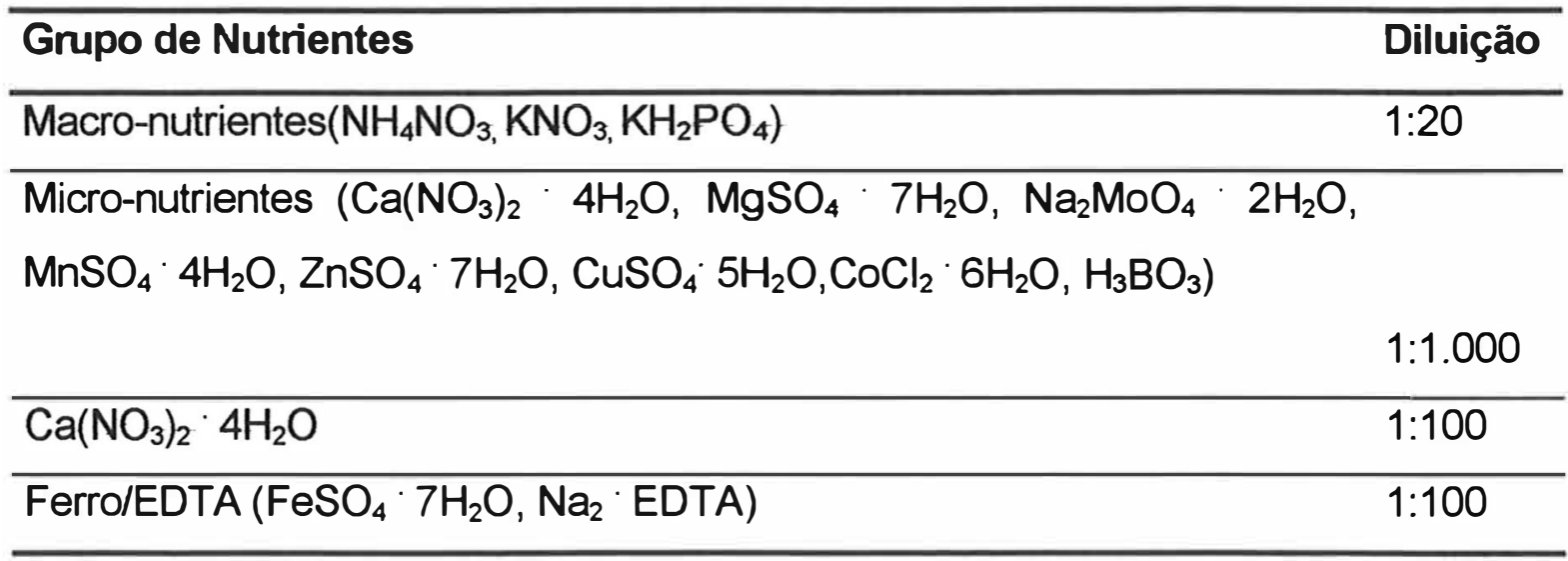

Os AP's foram construídos pela junção de dois frascos de $500 \mathrm{~mL}$, colocados um sobre o outro. O superior tendo forma bojuda, e o inferior tendo forma cilíndrica. Em ambos os frascos foi feito um furo com o diâmetro de 0,5 polegadas, localizada no seu terço inferior. Os frascos, ainda, eram dotados de tampa plástica, provida de uma vedação, tipo "O-ring" de diâmetro adequado e espessura de $2 \mathrm{~mm}$.

A ligação entre os frascos foi proporcionada por um tubo de vidro, que parte de 2 a $3 \mathrm{~mm}$ do fundo do frasco inferior, traspassando a sua tampa, bem como a tampa do frasco superior, e terminando 2 a $3 \mathrm{~mm}$ dentro do frasco superior. 


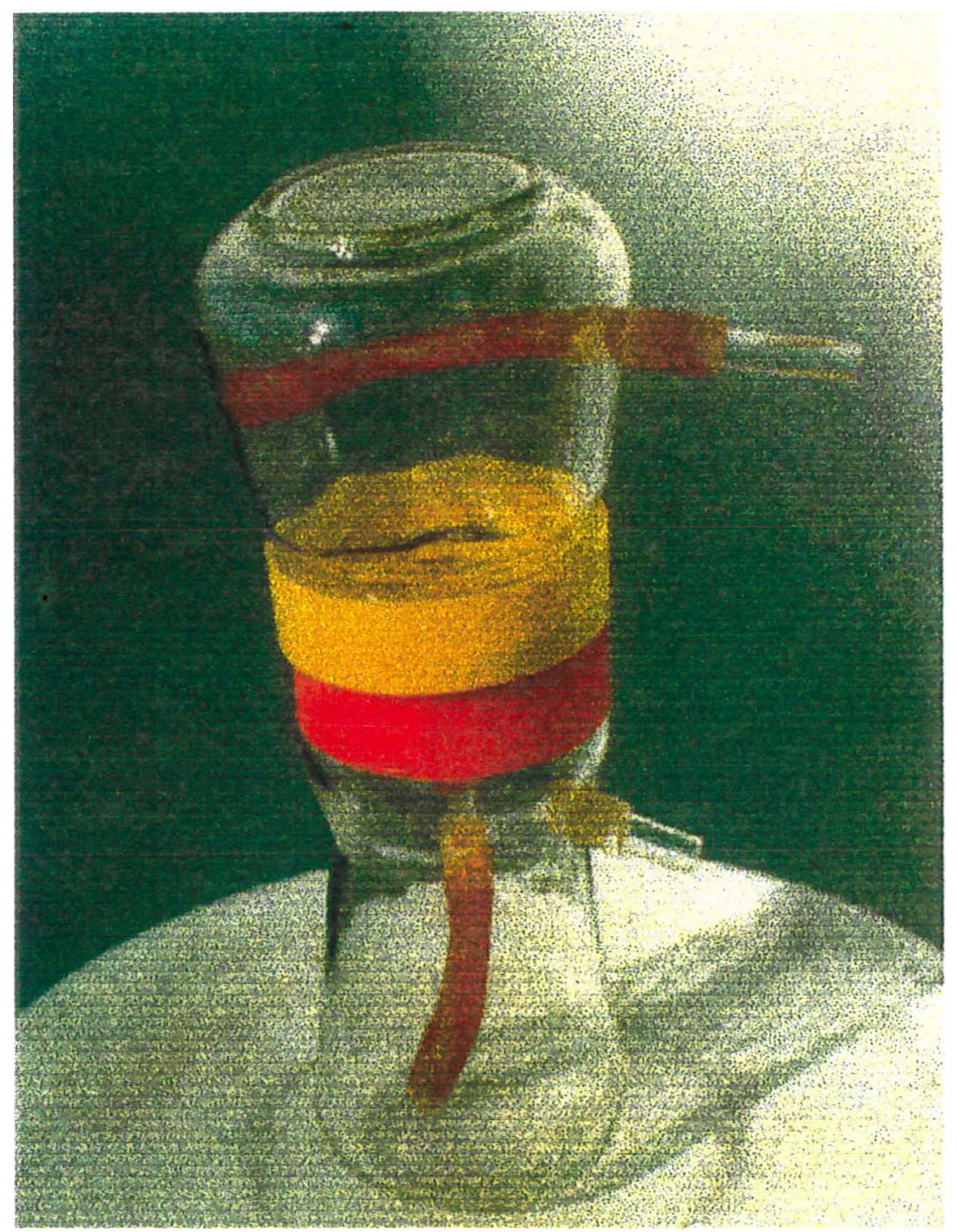

Figura 2. Foto do "aparato" descrito na página 28. 
A vedação desta ligação foi garantida pela passagem do tubo de vidro por dentro de um tubo de látex cirúrgico de diâmetro adequado (tubo de látex cirúrgico no. 104 ou 105).

Os furos existentes nos frascos inferior e superior também receberam este tipo de vedação. Através destes era feita a admissão e a exaustão do ar que promovia a movimentação do meio de cultura do frasco inferior para o frasco superior conforme esquema constante da Figura 3. O AP estava ligado a uma bomba de diafragma (renovador duplo de ar para aquário, modelo "Tropical II", marca Rebello \& Rebello).

Entre a bomba e o AP, foram colocados filtros de ar, feitos com segmentos de pipetas volumétricas de $10 \mathrm{~mL}$, preenchidos com fibra de vidro. As ligações são feitas com látex cirúrgico de diâmetro apropriado.

A freqüência do fluxo de ar foi regulada por um "timmer" Mallory, cuja regulagem permitia o acionamento da bomba, ou não, por intervalos mínimos de 15 minutos. Adotou-se uma regulagem para que se houvessem 8 ciclos por dia (um ciclo corresponde a 15 minutos de acionamento da bomba e mais 2 horas e 45 minutos de descanso).

Um sistema de válvulas permitia que o refluxo do meio ocorresse de modo rápido: 15 a 30 segundos depois da bomba desligada todo o meio estava no compartimento inferior do AP. A aeração promovia, não só a transferência do meio para o frasco superior, bem como uma vigorosa agitação, durante a qual os explantes eram movimentados.

\section{d. Descrição de um ensaio padrão}

O ponto inicial de um ensaio padrão era a repicagem de um lote de explantes do estoque. O estoque foi formado a partir de material obtido junto ao Laboratório de Fisiologia das Árvores do Departamento de Ciências Florestais da ESALQ-USP, e repicado continuamente a (freqüência de repicagem foi de 

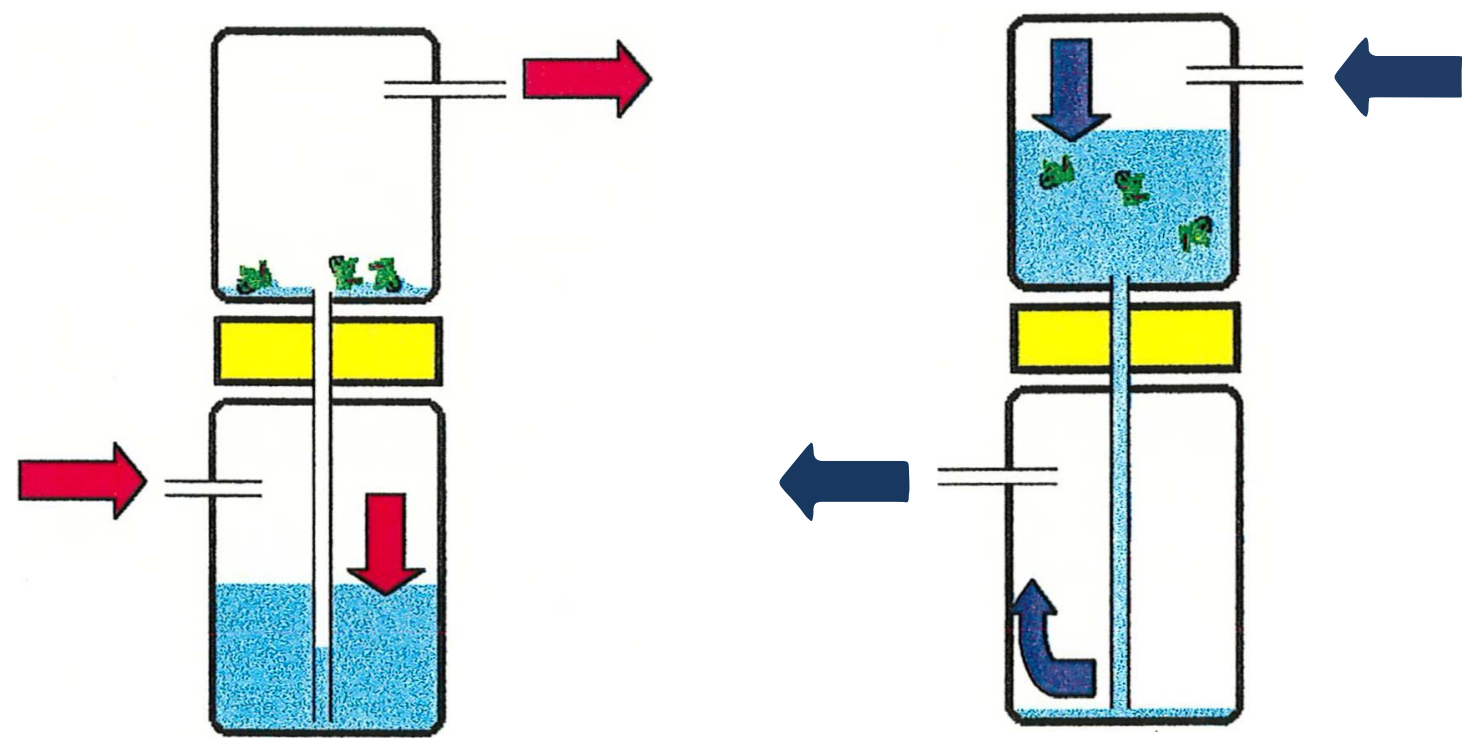

Figura 3. Esquema de funcionamento do aparato. No instante inicial, a ar, impulsionado pela bomba de aquário, percorre o caminho indicado pelas setas vermelhas, fazendo com que o líquido vá para o frasco superior. No instante seguinte, quando a bomba é paralisada pelo "timmer", a pressão atmosférica inverte o fluxo de ar, fazendo com que o líquido percorra o caminho indicado pelas seta azuis. Esta movimentação, 15 minutos a cada 2 horas, provoca a agitação e aeração do meio, além de movimentar de forma ativa os explantes no frasco superior. 
aproximadamente $20-25$ dias). O estoque era mantido em cerca de 180 frascos com 5 explantes em cada frasco.

A repicagem, a partir do estoque, tinha por objetivo obter explantes em grande atividade de crescimento, e como isso, segundo informações de CORREIA (1993) ocorre com 5 a 7 dias de crescimento em meio sólido, este era o tempo que se esperava até que os explante pudessem ser transferidos para o meio "A3". Composto por agar, açúcar e água, dai o nome "A3", este meio funciona de forma a equalizar dos explantes.

Definiu-se que os explantes permaneceriam neste meio por um período de 5 a 7 dias, tempo julgado suficiente para que os nutrientes absorvidos em excesso sejam metabolizados, porém insuficiente para que ocorressem danos aos tecidos. Explantes deixados no meio "A3" por tempo superior, dez ou doze dias por exemplo, começaram a apresentar sinais de problemas: encurtamento dos entrenós e surgimento de antocianina na superfície do explante.

Os explantes antes de serem colocados no meio "A3" eram "padronizados". A palavra padronização deve vir entre aspas, pois é muito difícil que uma padronização seja efetivamente feita. O procedimento adotado foi cortar os explantes em placa de Petri estéril, sob a qual se colocou um papel de filtro com um círculo de diâmetro de $8 \mathrm{~mm}$ desenhado em seu centro. Com auxílio de bisturi, e sob condições assépticas, os explante eram cortados de forma a ocupar a área do círculo.

As dificuldades observadas foram devidas a heterogeneidade dos tecidos dos explantes. Dos nós epicórmicos partem brotações de tamanho variável que ficam presas pela base em tecido mais lignificado. A exclusão da base provoca a desagregação total do explante, então é necessário que se mantenha pelo menos um pouco deste tecido para que o explante se mantenha integro, daí surgindo os problemas na padronização dos explantes.

A garantia da validade dos ensaios foi dada pela utilização de explantes com massas de matéria fresca muito semelhantes. Outra providência adotada no 
sentido da homogeneidade dos explantes foi a utilização de 5 explantes por ensaio. Assim, enquanto um grupo de cinco explantes era imediatamente congelado como testemunha, outro grupo de mais cinco explantes eram utilizados como inoculo inicial.

Obter massas iguais exigiu a utilização do seguinte procedimento: frascos de $250 \mathrm{ml}$, de pesos iguais, foram separados aos pares (calibração). A verificação dos pesos foi feita com balança analítica de pratos, cuja sensibilidade é de $5 \mathrm{mg}$. Os frascos limpos, tarados, eram autoclavados. Depois, sob condições assépticas, 10 explantes retirados do meio "A3" eram divididos em dois grupos de cinco exemplares cada, e colocados em um par de frascos esterilizados, acima descritos, e tampados. Feito isto, os frascos eram levados até a balança analítica de pratos e comparados.

O frasco de estivesse mais pesado era então aberto, e com auxílio de bisturi, e sem mais preocupações com a assepsia, retirava-se segmentos de um explante até que os pratos se equilibrassem novamente (é importante lembrar que os frascos já tinham o mesmo peso antes do início do procedimento). O frasco que não foi aberto voltava para o fluxo laminar para ser repicado para um AP, enquanto que o frasco aberto era separado para ser a testemunha do ensaio.

Os explantes iniciais, sempre em número de 5 , foram repicados, de forma asséptica, para o AP anteriormente esterilizado, e já com $125 \mathrm{ml}$ de meio JADS líquido. O primeiro passo para a repicagem é abrir o AP em sua parte superior, o que era feito desrosqueando-se a porção de vidro da tampa plástica. Então, os cinco explantes eram transferidos com auxílio de pinça para dentro do AP. Terminada a operação as tampas eram envolvidas com filme de PVC para garantir a esterilidade naquela região crítica. Os filtros eram conectados e o AP colocado na sala de crescimento para o início do ensaio. Imediatamente após a montagem do AP o mesmo era testado para que se pudesse detectar vazamentos. Não os observando, o tempo do ensaio começa a ser contado.

Os explantes que não foram repicados são conservados congelados até o 
momento de se proceder à pesagem dos mesmos. A temperatura do "freezer" doméstico era de aproximadamente $-18^{\circ} \mathrm{C}$.

Decorrido o tempo prefixado para cada ensaio, o AP era desconectado dos filtros e aberto, então os explantes levados para o "freezer". O meio líquido que sobrava tinha o seu $\mathrm{pH}$ medido, e então transferido para um frasco de $250 \mathrm{~mL}$ limpo e colocado no "freezer" para análises posteriores.

No momento da abertura do AP era verificada a presença de contaminantes microbianos. Primeiramente pelo aspecto visual, se havia crescimento de fungos ou mesmo turvamento do meio, posteriormente pelo $\mathrm{pH}$. A presença de contaminação microbiana, mesmo que não visivel a olho nu proporciona uma queda sensivel no $\mathrm{pH}$ do meio que sobra no AP.

\section{e. Ensaios de padronização dos explantes.}

Os ensaios para a padronização dos explantes foram feitos utilizando-se da padronização visual, utilizando-se de um vazador; ou com o protocolo descrito no item anterior. A padronização visual é feita em condições assépticas, sobre papel toalha estéril; e o operador tenta obter explantes o mais homogêneos possivel. Aqui a experiência do operador é fundamental, e trabalhar com a contagem do número de brotações é uma preciosa indicação para se conseguir a homogeneidade dos explantes. No entanto, o fator subjetivo tem interferência decisiva neste procedimento, o que não pode ser aceitável como procedimento padrão.

O vazador é constituído de um corpo de aço tendo uma das pontas oca e as bordas afiadas: A ponta oca do vazador utilizado permite que se consiga furos de $11 \mathrm{~mm}$ diâmetro: A desinfeção do vazador foi feita pela ação da imersão em álcool etílico $96^{\circ} \mathrm{GL}$, seguida de flambagem em chama de lamparina dentro da capela de fluxo laminar; momentos antes da utilização. Devido ao diâmetro do furo do vazador é necessário que se utilize explantes de tamanho grande (aproximadamente 1,0- 
1,5 gramas de peso fresco). Sobre papel toalha estéril o material vegetal é submetido à ação do vazador. O conteúdo retido dentro do utensílio é recuperado com auxílio de pinça.

A homogeneidade dos explantes foi conferida com o auxílio de pesagem em balança analítica eletrônica (Mettler, modelo H31 AR). Quando se trata de peso da matéria seca, a secagem foi feita em estufa marca FANEN, modelo 219 , mantida, por um período nunca inferior a 48 horas, na temperatura de $60^{\circ} \mathrm{C}$.

\section{f. Estatistica.}

Os testes de homogeneidade dos explantes foram analisados medindo-se o Coeficiente de Variação (CV\%), segundo definição proposta por Gomes (1963): Valores abaixo de 10\%, classificados por Gomes (1963) como baixos, foram aceitos como razoáveis, segundo recomendação de Couto (1995), para cultivos "in vitro" devido a estabilidade do ambiente neste tipo de cultivo. $\mathrm{O}$ CV\% foi calculado segundo a fórmula:

$$
\begin{aligned}
& \text { CV\% }=(\mathrm{s} / \mathrm{m}) \times 100, \text { onde } \\
& \mathrm{s}=\text { desvio padrão; } \\
& \mathrm{m} \equiv \text { média. }
\end{aligned}
$$

Os cálculos foram realizados com uma calculadora marca Hewlett-Packard, modelo HP 15C. As regressões e ajustes de curvas foram feitas segundo modelo computacional proposto por Zullo Júnior \& Arruda (1986), enquanto que comparações de médias foram feitas utilizando-se o teste de Tukey, como proposto por Gomes (1963). 


\section{RESULTADOS E DISCUSSÃO.}

\subsection{Padronização dos explantes.}

A cultura "in vitro" apresenta uma dificuldade muito grande no que se refere a quantificação do crescimento, e parte deste problema se deve à dificuldade na padronização dos explantes. Os problemas são devidos, principalmente, à heterogeneidade do material dos explantes em geral e, no caso específico deste trabalho, em que a micropropagação de eucalipto é feita utilizando-se como explantes nós.

O tema padronização de explantes é raramente abordado na literatura, e em geral quando o fazem, a massa não é o parâmetro mais utilizado. A contagem do número de brotações contidas no explante é a característica mais comum relatada na bibliografia que aborda a padronização, como por exemplo Alvard et al. (1993); Correia (1993). Neste caso a medida de crescimento é feita como uma função do número de brotações novas, ou mesmo do desenvolvimento destas. Este sistema é válido quando se trabalha com propagação em larga escala do material, pois o produto final da cultura é o maior número possível de microestacas.

Muito embora seja a contagem de brotações seja o critério mais adotado, por ser mais fácil e mais exato, no entanto, para se trabalhar com um modelo cinético de crescimento é necessário que se trabalhe com massas, e mais, que se tenha uma padronização confiável, uma vez que os ensaios deverão ser destrutivos na maior parte das vezes.

Duas ordens de problemas estão envolvidos na padronização dos explantes: 
uma quantitativa e outra fisiológica, pois não basta que os explantes tenham massas equivalentes, é necessário que eles estejam em estágio fisiológico semelhante para que os resultados sejam comparáveis.

Ambas as questões são de solução complexa, muito embora a questão fisiológica seja mais difícil de ser abordada. A ausência de indicadores quantitativos externos é o principal problema, então a adoção de procedimentos preventivos parece ser a solução mais adequada para solucionar esta questão.

A prevenção consiste em se tomar todos os cuidados para que no momento do início dos ensaios todos os explantes estejam em condições fisiológicas idênticas.

O primeiro passo para que os explantes, a partir do estoque, adquiram grande atividade de crescimento é proceder repicagem para meio sólido fresco. Segundo Correia (1993) o pico de crescimento em meio JADS ocorre aproximadamente entre 5 e 7 dias de cultivo. Então 0 intervalo proposto no protocolo, de 7 a 10 dias, foi fixado como suficiente para se garantir grande atividade para o material.

Em segmentos de plantas de eucalipto, como os utilizados neste trabalho, os órgãos especializados em absorção de nutrientes encontram-se ausentes. Então é através das paredes das células do explante que os nutrientes minerais irão suprir os meristemas e, muito embora haja uma seletividade neste processo, é muito possivel que alguns dos nutrientes sejam absorvido em excesso em relação a outros. A existência deste comportamento no processo de micropropagação não é uma questão definida como afirmou Leifert et al. (1995), embora haja evidências de que ocorra, por exemplo com o potássio, e não ocorra com o zinco (Willians (1992) ${ }^{1}$, citado por Leifert et al. 1995).

\footnotetext{
${ }^{1}$ WILLIANS, R.R. Towards a model of mineral uptake in vitro. In: KURATA, K; KOZAI, T. Transplant Productions Systems. Dordrecht, NL: Kluwer Academic Publishers, 1992. p. 213-219.
} 
A garantia de que os explantes estão no mesmo estágio nutricional é obtida com a repicagem dos explantes para o meio "A3", por um período de 5 a 7 dias. Como este meio fornece somente as condições físicas e açúcar, o crescimento dos explantes se dará as custas da fonte de carbono e do consumo dos nutrientes minerais em excesso. Com isso todos os explantes estarão em estado nutricional semelhante, possibilitando a comparação do crescimento. Não é desejável que a deficiência nutricional seja prolongada. Caso isto aconteça ocorre a formação de antocianina, com o desenvolvimento de cor avermelhada sobre os explantes. As possíveis variações fisiológicas entre um explante e outro, devidas a heterogeneidade do material é atenuada pela repicagem de 5 (cinco) explantes em cada AP.

O passo seguinte é a padronização dos mesmos em relação à massa, passo imprescindivel para a adoção de procedimentos mais quantificáveis. Três tipos de procedimentos foram testados: padronização visual; padronização com a utilização de um vazador; e padronização visual seguida da equalização das massas dos explantes.

O trabalho cotidiano com o cultivo "in vitro" permite ao operador com alguma experiência cortar os explantes de tamanho equivalentes. Este tipo de padronização foi utilizado no cultivo de brotações de eucalipto por Correia (1993).

Vinte explantes foram padronizados pelo método visual para que se pudesse determinar a homogeneidade do lote. Buscou-se manter cada explante com diâmetro de $1 \mathrm{~cm}$, e massa (peso da matéria fresca) de $300 \mathrm{mg}$ aproximadamente. Segundo Couto (1995), o conjunto poderia ser considerado razoavelmente homogêneo, em se tratando de cultura "in vitro", se o coeficiente de variação (CV\%) ficasse abaixo de $10 \%$.

KOZAI, T. Transplant Productions Systems. Dordrecht, NL: Kluwer Academic Publishers, 1992. p. 213-219. 
Os valores resultantes deste ensaio de homogeneização pelo método visual, em termos de peso da matéria fresca, encontram-se na tabela 4, página 40.

Como uma forma de diminuir a subjetividade da padronização visual foi testada a utilização de um vazador de aço com a finalidade de se obter explantes de tamanhos equivalentes.

$O$ resultado das pesagens destes explantes, em termos de peso da matéria fresca, encontram-se na Tabela 5 da página 41. É importante observar que a utilização do vazador, em que se pese a obtenção de homogeneidade maior, causa excessivos danos a superfície dos explantes devido ao corte e esmagamento de tecidos.

Pode-se notar que os explantes obtidos com este procedimento apresentavam um grau mais elevado de oxidação fenólica em relação àqueles cortados com o auxílio de bisturi. Alguns explantes bastante danificados não apresentavam crescimento por muito tempo após tal procedimento.

O terceiro método testado para padronizar os explantes antes dos ensaios, descrito no item "d. Descrição de um ensaio padrão" do capítulo anterior. Os resultados encontram-se na Tabela 6, página 42.

Os dados da pesagem de 21 explantes constantes na Tabela 6. foram obtidos segundo o método da padronização visual seguida da equalização das massas dos explantes. Neste caso foi feita a pesagem do material em termos de peso de matéria fresca e também peso da matéria seca para que pudesse calcular o coeficiente de variação. A Tabela 7., da página 43, apresenta a síntese dos resultados dos três tipos de metodologia empregados para a padronização dos explantes.

A análise da Tabela 7. indica que a terceira metodologia testada mostra-se muito aceitável como forma de padronização dos explantes em se tratando de peso da matéria fresca. O CV\% de 4,18\% indica que há uma diferença muito pequena entre os explantes que são congelados como testemunha de cada ensaio destrutivo e aqueles que são repicados para os AP. 
Tabela 4. Peso da matéria fresca de explantes de eucalipto, clone "H10", obtidos durante a realização de teste de homogeneidade pelo método de padronização visual.

\begin{tabular}{|c|c|}
\hline Explante & $\begin{array}{c}\text { Peso da Matéria Fresca* } \\
\text { (gramas) }\end{array}$ \\
\hline 1 & 0,335 \\
\hline 2 & 0,347 \\
\hline 3 & 0,198 \\
\hline 4 & 0,303 \\
\hline 5 & 0,158 \\
\hline 6 & 0,353 \\
\hline 7 & 0,294 \\
\hline 8 & 0,484 \\
\hline 9 & 0,368 \\
\hline 10 & 0,281 \\
\hline 11 & 0,242 \\
\hline 12 & 0,228 \\
\hline 13 & 0,104 \\
\hline 14 & 0,181 \\
\hline 15 & 0,131 \\
\hline 16 & 0,165 \\
\hline 17 & 0,148 \\
\hline 18 & 0,126 \\
\hline 19 & 0,118 \\
\hline 20 & 0,098 \\
\hline
\end{tabular}


Tabela 5. Peso da matéria fresca de explantes de eucalipto, clone "H10" obtidos com o auxílio de um vazador de metal com tamanho padrão de $11 \mathrm{~mm}$ de diâmetro.

\begin{tabular}{|c|c|}
\hline Explante & $\begin{array}{c}\text { Peso da Matéria Fresca* } \\
\text { (gramas) }\end{array}$ \\
\hline 1 & 0,411 \\
\hline 2 & 0,361 \\
\hline 3 & 0,314 \\
\hline 4 & 0,406 \\
\hline 5 & 0,330 \\
\hline 6 & 0,303 \\
\hline 7 & 0,448 \\
\hline 8 & 0,229 \\
\hline 9 & 0,272 \\
\hline 10 & 0,219 \\
\hline 11 & 0,351 \\
\hline 12 & 0,395 \\
\hline 13 & 0,325 \\
\hline 14 & 0,376 \\
\hline 15 & 0,350 \\
\hline 16 & 0,459 \\
\hline 17 & 0,375 \\
\hline 18 & 0,440 \\
\hline 19 & 0,261 \\
\hline 20 & 0,338 \\
\hline 21 & 0,307 \\
\hline 22 & 0,409 \\
\hline 23 & 0,513 \\
\hline 24 & 0,422 \\
\hline
\end{tabular}


Tabela 6. Peso da matéria fresca e peso da matéria seca de explantes de eucalipto, clone "H10" obtidos pelo método de padronização visual, seguido da equalização das massas dos explantes através de equilibrio em frascos prétarados.

\begin{tabular}{|c|c|c|}
\hline Explante & Peso da Matéria Fresca* $(\mathrm{g})$ & Peso da Matéria Seca* (g) \\
\hline 1 & 0,3895 & 0,0167 \\
\hline 2 & 0,4184 & 0,0250 \\
\hline 3 & 0,3825 & 0,0256 \\
\hline 4 & 0,3835 & 0,0257 \\
\hline 5 & 0,4255 & 0,0297 \\
\hline 6 & 0,4201 & 0,0415 \\
\hline 7 & 0,3999 & 0,0273 \\
\hline 8 & 0,4111 & 0,0295 \\
\hline 9 & 0,4260 & 0,0211 \\
\hline 10 & 0,4174 & 0,0294 \\
\hline 11 & 0,4121 & 0,0326 \\
\hline 12 & 0,3980 & 0,0213 \\
\hline 13 & 0,3854 & 0,0254 \\
\hline 14 & 0,4469 & 0,0309 \\
\hline 15 & 0,4264 & 0,0346 \\
\hline 16 & 0,4265 & 0,0269 \\
\hline 17 & 0,4154 & 0,0330 \\
\hline 18 & 0,3985 & 0,0257 \\
\hline 19 & 0,4116 & 0,0308 \\
\hline 20 & 0,4151 & 0,0318 \\
\hline 21 & 0,4300 & 0,0298 \\
\hline
\end{tabular}

* = Pesagens feitas em balança analítica eletrônica com precisão de $0,1 \mathrm{mg}$. 
Tabela 7. Síntese dos resultados dos três tipos de metodologia empregados para a padronização dos explantes de eucalipto, clone "H10". Valores em gramas de peso da matéria fresca.

\begin{tabular}{lcccc}
\hline Método & $\begin{array}{c}\text { Tamanho da } \\
\text { Amostra }(\mathbf{n})\end{array}$ & $\begin{array}{c}\text { Média } \\
(\mathrm{m})\end{array}$ & $\begin{array}{c}\text { Desvio } \\
\text { Padrão } \\
(\mathbf{s})\end{array}$ & $\begin{array}{c}\text { Coef. de } \\
\text { Variação } \\
(\mathbf{C V} \%)\end{array}$ \\
\hline Visual (a) & 20 & 0,233 & 0,108 & 46,33 \\
\hline Vazador (a) & 24 & 0,359 & 0,074 & 20,58 \\
\hline Visual + Equaliz. (a) & 21 & 0,4116 & 0,0172 & 4,18 \\
\hline Visual + Equaliz. (b) & 21 & 0,0283 & 0,053 & 18,78 \\
\hline
\end{tabular}

a = Base: Peso da Matéria Fresca.

b = Base: Peso da Matéria Seca.

O mesmo não pode ser afirmado com relação ao peso da matéria seca. $\mathrm{A}$ discrepância entre as medidas deve ser imputada à forma dos explantes que acabam retendo quantidades distintas de água.

\subsection{Correlação entre peso da matéria fresca e peso da matéria seca.}

A construção da curva de crescimento foi feita através de ensaios destrutivos. Os explantes são destruídos ao final de cada intervalo de tempo predeterminado, e então são desidratados para a determinação do peso da matéria seca. A vantagem da utilização desta forma de medida é reconhecida por vários autores (Hunt, 1982; Correia, 1993; Leifert, 1995).

No entanto, a padronização do explante deve ser feita em relação ao peso da matéria fresca, uma vez que os mesmos deverão crescer para que se possa 
construir a curva de crescimento. A metodologia de padronização descrita no item anterior garante uma boa confiabilidade entre a igualdade das massas do explante testemunha e daqueles que irão crescer no AP.

Para solucionar este problema de padronização em termos de peso da matéria fresca e obtenção de dados em peso da matéria seca é necessário que se obtenha uma correlação confiável entre o peso da matéria fresca e o peso da matéria seca. Trinta e três explantes de tamanhos variados do clone "H10" foram coletados e pesados. Os valores em termos de peso da matéria fresca e peso da matéria seca encontram-se na Tabela 8, da página 45.

Os dados da Tabela 8. foram transformados em gráfico (Figura 4) e feita a regressão linear dos pontos obtidos acrescentando-se o par de pontos zero/zero. A inclusão deste último par de pontos (zero/zero) tem razão de ser sob ponto de vista biológico, pois a ausência de massa em termos de peso da matéria fresca deverá, necessariamente, corresponder a ausência de massa em termos de peso da matéria seca.

O ajuste dos pontos foi feito segundo metodologia computacional proposta por Zullo Júnior \& Arruda (1986). O ajuste linear com 34 pares de pontos gerou a equação:

$$
\mathrm{PMS}=0,125+0,0751 \text { PMF (gramas) }
$$

O coeficiente de correlação da regressão linear ( $r$ ) para a equação acima é de 0,9080 , indicando um bom ajuste dos pontos, e determinando que existe correlação significativa entre o peso da matéria fresca e o peso da matéria seca de explantes de eucalipto clone "H10".

Segundo Correia (1993), o clone "H10" apresenta, em média, o peso da matéria seca correspondente a $10,8 \%$ do peso da matéria fresca. Porém os dados obtidos pela equação acima indicam que este valor pode ser um pouco superior, cerca de $20 \%$. A discrepância pode ser explicada pela diferença entre a quantidade 
Tabela 8. Valores de peso da matéria fresca e peso da matéria seca de explantes de eucalipto, clone "H10", medidos para determinar a correlação entre estas duas medidas.

\begin{tabular}{|c|c|c|c|c|c|c|c|c|}
\hline $\begin{array}{c}\text { Explante } \\
\text { no. }\end{array}$ & $\begin{array}{l}\text { Peso da } \\
\text { M.Materia } \\
\text { Fresca } \\
\text { (gramas) }\end{array}$ & $\begin{array}{l}\text { Peso dil } \\
\text { Materia } \\
\text { Seca } \\
\text { (gramasł }\end{array}$ & $\begin{array}{c}\text { Explante } \\
\text { no. }\end{array}$ & $\begin{array}{l}\text { Peso cia } \\
\text { Materia } \\
\text { Fresca } \\
\text { (gramas) }\end{array}$ & $\begin{array}{c}\text { Peso cia } \\
\text { Materia } \\
\text { Seca } \\
\text { (gramas) }\end{array}$ & $\begin{array}{c}\text { Explante } \\
\text { no. }\end{array}$ & $\begin{array}{l}\text { Peso da } \\
\text { Materia } \\
\text { Fresca } \\
\text { (gramas) }\end{array}$ & $\begin{array}{l}\text { Peso da } \\
\text { Matéria } \\
\text { Fresca } \\
\text { igramasi }\end{array}$ \\
\hline 1 & 1,1394 & 0,2135 & 12 & 2,5075 & 0,2760 & 23 & 0,2237 & 0,1524 \\
\hline 2 & 2,2105 & 0,3932 & 13 & 3,2721 & 0,3569 & 24 & 0,8809 & 0,1847 \\
\hline 3 & 0,5072 & 0,1747 & 14 & 1,8216 & 0,2671 & 25 & 0,4474 & 0,1534 \\
\hline 4 & 0,2190 & 0.1461 & 15 & 2,3190 & 0,2953 & 26 & 0,4013 & 0,1611 \\
\hline 5 & 1,118 & 0.1983 & 16 & 1,3830 & 0,2321 & 27 & 0,2125 & 0,1441 \\
\hline 6 & 0,1662 & 0.1423 & 17 & 1,4483 & 0,2356 & 28 & 0,5605 & 0,1734 \\
\hline 7 & 1,3617 & 0.2629 & 18 & 0,4196 & 0,1635 & 29 & 0,8966 & 0,2013 \\
\hline 8 & 1,2522 & 0.2356 & 19 & 1,3577 & 0,2169 & 30 & 1,6072 & 0,2366 \\
\hline 9 & 1,0568 & 0.2017 & 20 & 2,6583 & 0,3021 & 31 & 3,1442 & 0,3210 \\
\hline 10 & 0,8490 & 0.2142 & 21 & 2,3080 & 0,2944 & 32 & 0,1589 & 0,1418 \\
\hline 11 & 0,1656 & 0.1435 & 22 & 1,5230 & 0,2537 & 33 & 0,2818 & 0,1519 \\
\hline
\end{tabular}

de material lignificado da base dos nó epicórmicos utilizados para a obtenção dos explantes em uma e outra ocasião. Procedimento equivalente adotado para o clone "G5" (Eucalyptus grandis) determinou como 10,98\% a percentagem de peso da matéria seca em relação ao peso da matéria fresca (Gonçalves \& Gonçalves, 1998). 


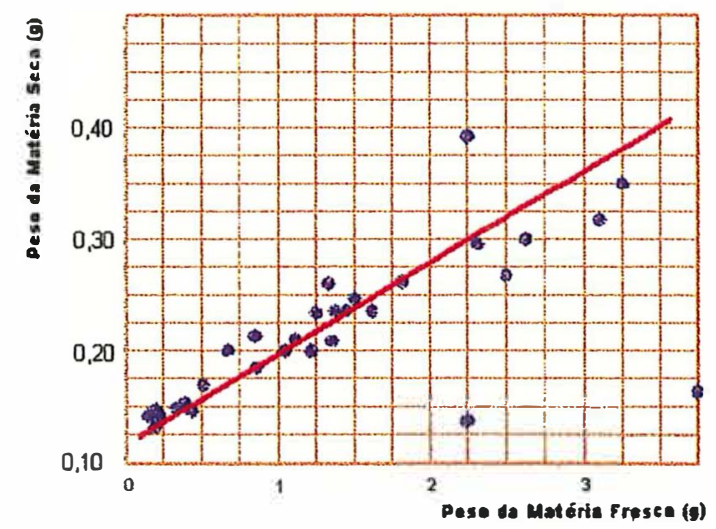

Figura 4. Gráfico originário da Tabela 8 , mostrando a correlação entre a Massa da Matéria Seca e a Massa da Matéria Fresca do clone "H-10" de Eucalipto. 


\subsection{A curva de crescimento e o cálculo de $\mu$.}

No âmbito deste trabalho a expressão "curva de crescimento" deverá ser entendida como a figura em forma de "S" obtida quando da representação em gráfico, do incremento da massa em função do tempo.

Os resultados experimentais de crescimento de plantas podem ser ajustados por vários tipos de equações, implicando em modelos com uma aproximação maior ou menor da realidade observada. No entanto, existe uma uniformidade de opinião entre os pesquisadores que trabalham com o crescimento de plantas, de que a curva de crescimento é aquela que possibilita uma melhor descrição do fenômeno, sob ponto de vista matemático e estatístico (Causton \& Venus, 1981; Hunt, 1982).

A partir da curva de crescimento $(X=X(t)$, onde $X=$ massa dos explantes; $t$ $=$ tempo em dias) é possível calcular $o$ valor de $\mu$, dado pela equação, $\mu=1 / X$ (dX/dt), pela integração dos valores experimentais. A condição matemática para que possa ser feita a integração é que a velocidade específica de crescimento se mantenha constante e diferente de zero. Isto ocorre no setor "II" da curva da Figura 5 , quando então a equação acima pode ser integrada entre os limites $t_{1}, X_{1}$ e $t_{2}, X_{2}$ resultando na equação que é a base do crescimento exponencial (Dias, 1982) (ver Equação 2).

Considerando-se a limitação matemática acima exposta, pode-se aplicar logaritmo a ambos os lados da equação obtendo-se:

$$
\begin{aligned}
& \operatorname{Ln} X_{2}=\operatorname{Ln} X_{1}\left[\mu\left(t_{2}-t_{1}\right)\right] \text { ou } \\
& \operatorname{Ln}\left(X_{2}-X_{1}\right)=\mu \Delta t,
\end{aligned}
$$

Logo, colocando em forma de gráfico o resultado da equação Eq. 6 com os valores experimentais é possível, por uma regressão linear dos pontos obter a velocidade específica de crescimento.

Foram realizados 19 ensaios para a obtenção dos dados constantes da 
Tabela 9 da página 49. Os valores assinalados com os símbolos 9' e 9", por exemplo, significam segunda e terceira repetições, respectivamente. Os valores referentes ao peso de explantes constantes da Tabela 9. são o resultado da pesagem conjunta dos 5 explantes repicados para os "AP", e suas respectivas testemunhas. A Tabela 9 apresenta também os valores de $\mathrm{pH}$ medidos ao final de cada ensaio. Os valores de pH referentes aos pontos 9' a 15" não foram coletados.

O gráfico da Figura 6 foi construído tendo como eixo das ordenadas os valores de (PSF-PSI) da Tabela 9 e no eixo das abscissas os valores de tempo, medido em dias. O gráfico da Figura 7, por sua vez, foi construída com os valores Ln (PSF-PSI) da Tabela 9. no eixo das ordenadas contra os valores de tempo, medido em dias, no eixo das abscissas. Em ambos os casos o ponto $(0,0 ; 0,0)$ foi desconsiderado na construção dos gráficos, por não haver sentido biológico a sua inclusão.

Apesar de haver uma dispersão razoável nos últimos pontos da Figura 3. pode-se observar que o ajuste dos pontos por uma curva de crescimento é adequado. A coincidência dos pontos relativos aos dias 1 e 2 pode ser atribuída ao erro relativo da padronização dos explantes quando medidos em peso da matéria seca. Mais repetições destes pontos, com a aplicação de uma faixa de erro devido ao desvio padrão, deixará claro a argumentação acima.

O ponto referente ao "dia 4" está claramente fora da curva. Não existe uma explicação biológica para o fato dos explante não terem crescido, uma vez que os mesmos são repicados em quintuplicatas. Os dois primeiros dias não apresentam crescimento indicando que há, mesmo que pequena, uma fase lag no processo.

Este período em uma curva de crescimento é considerado como o tempo de ajuste a novas condições. Em se tratando de microorganismos a fase lag, muito embora não apresente crescimento mensurável, está longe de ser uma fase de dormência. Quantidades consideráveis de nutrientes podem ser consumidas, e provavelmente utilizadas na síntese de novas enzimas que possibilitarão o máximo aproveitamento do novo ambiente. (Gaudy Junior \& Gaudy, 1981). 
Tabela 9. Valores de $\mathrm{pH}$, peso da matéria seca inicial, final, diferença de peso da matéria seca inicial e final, e logaritmo neperiano da diferença de peso da matéria seca inicial e final, de 19 ensaios experimentais de crescimento de nós epicórmicos de eucalipto, clone "H10", "in vitro".

\begin{tabular}{cccccc}
\hline $\begin{array}{c}\text { Tempo } \\
\text { (dias) }\end{array}$ & pH & $\begin{array}{c}\text { Peso Seco } \\
\text { Inicial (PSI) } \\
\text { (gramas) }\end{array}$ & $\begin{array}{c}\text { Peso Seco } \\
\text { Final (PSF) } \\
\text { (gramas) }\end{array}$ & $\begin{array}{c}\text { PSF - PSI } \\
\text { (gramas) }\end{array}$ & Ln (PSF-PSI) \\
\hline 0 & $5,3(a)$ & - & - & - & - \\
\hline 1 & 5,8 & 0,1340 & 0,1513 & 0,0173 & $-4,0570$ \\
\hline 2 & 5,7 & 0,0679 & 0,0852 & 0,0173 & $-4,0570$ \\
\hline 3 & 5,6 & 0,1346 & 0,1558 & 0,0212 & $-3,8538$ \\
\hline 4 & 5,6 & 0,1861 & 0,1854 & $-0,0007(b)$ & - \\
\hline 5 & 5,4 & 0,0977 & 0,1551 & 0,0574 & $-2,8577$ \\
\hline 6 & 5,4 & 0,1004 & 0,2107 & 0,1103 & $-2,2046$ \\
\hline 7 & 5,4 & 0,1162 & 0,2563 & 0,1401 & $-1,9654$ \\
\hline 8 & 5,4 & 0,1110 & 0,3104 & 0,1994 & $-1,6124$ \\
\hline 9 & 5,4 & 0,1273 & 0,2717 & 0,1444 & $-1,9352$ \\
\hline 11 & 5,1 & 0,0966 & 0,2697 & 0,1731 & $-1,7539$ \\
\hline 13 & 5,6 & 0,0986 & 0,2595 & 0,1609 & $-1,8270$ \\
\hline 15 & 5,8 & 0,1310 & 0,3812 & 0,2502 & $-1,3855$ \\
\hline $9^{\prime}$ & (c) & 0,0606 & 0,2028 & 0,1422 & $-1,9505$ \\
\hline $11^{\prime}$ & (c) & 0,1167 & 0,2711 & 0,1544 & $-1,8682$ \\
\hline $13^{\prime}$ & (c) & 0,1441 & 0,2224 & 0,0783 & $-2,5472$ \\
\hline $9{ }^{\prime \prime}$ & (c) & 0,1698 & 0,3318 & 0,1620 & $-1,8202$ \\
\hline $11^{\prime \prime}$ & (c) & 0,1642 & 0,2564 & 0,0922 & $-2,3838$ \\
\hline $13^{\prime \prime}$ & (c) & 0,1329 & 0,3203 & 0,1874 & $-1,6745$ \\
\hline $15^{\prime \prime}$ & (c) & 0,1179 & 0,2991 & 0,1812 & $-1,7082$ \\
\hline & & & & \\
\hline
\end{tabular}

$a=$ Média de 4 repetições. $b=$ Ausência de crescimento devido a causa desconhecida. $c=$ Valor não coletado. Os valores seguidos de ' ou " são repetições de um mesmo tempo. 


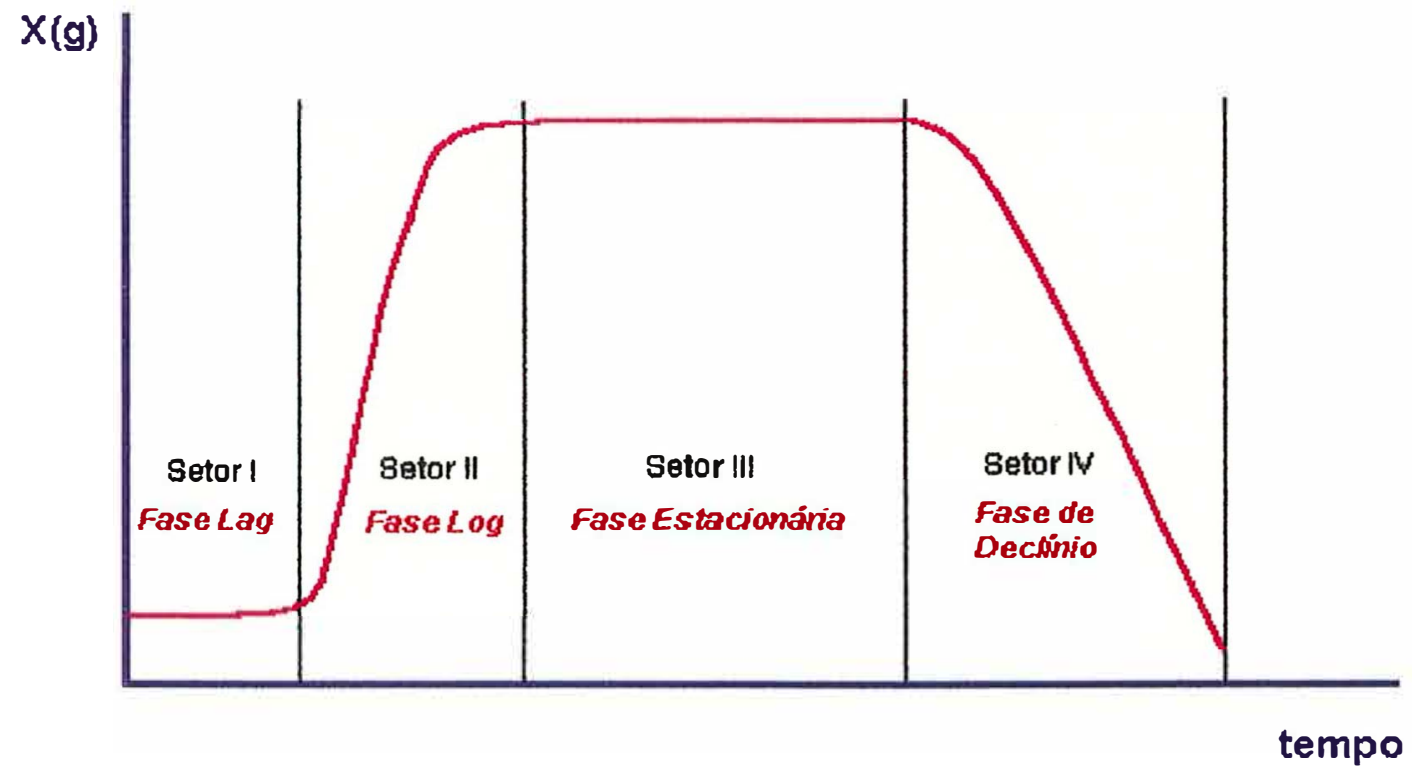

Figura 5. Curva de crescimento padrão. 


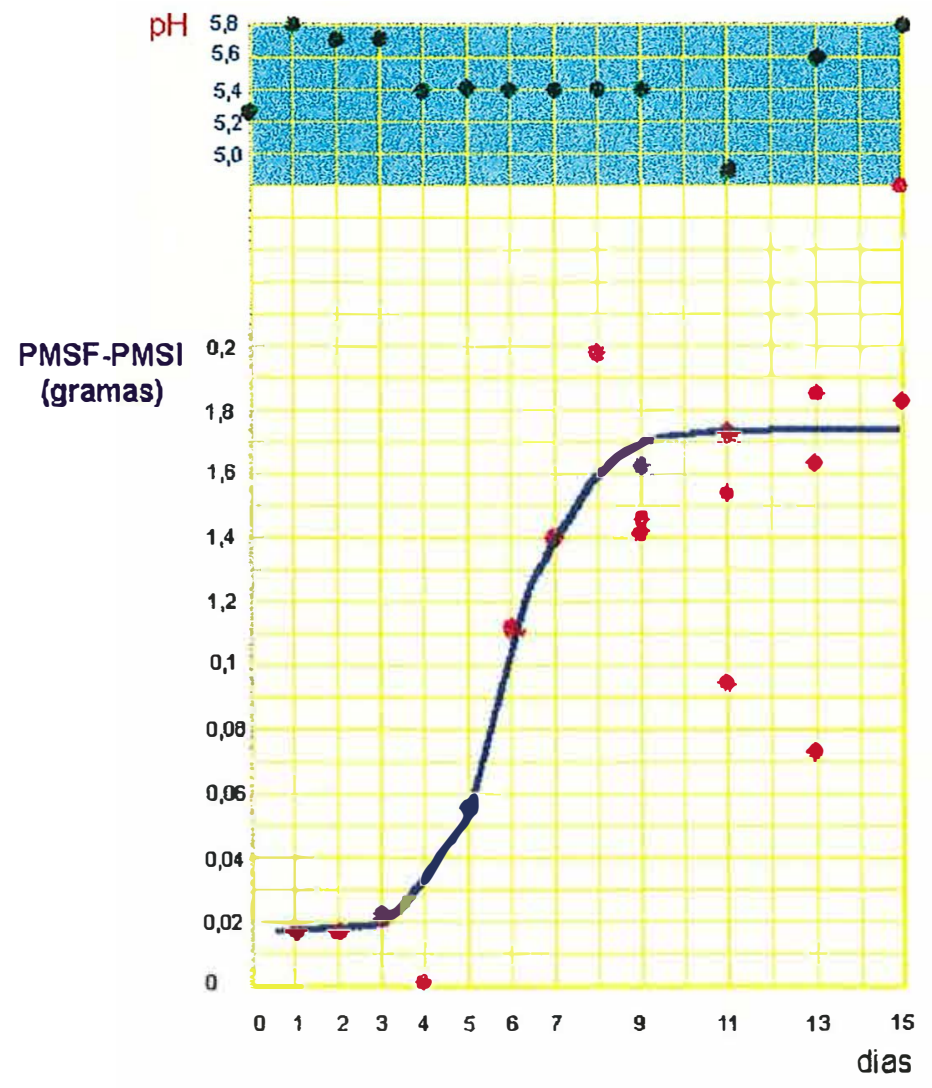

Figura 6. Curva de crescimento obtida a partir dos dados de PMSF (Peso da Matéria Seca Final) menos o PMSI (Peso da Matéria Seca Inicial) contra o tempo em dias. Na parte superior da figura encontram-se os valores de $\mathrm{PH}$ obtidos ao final de cada.ensaio. 
Para plantas não existem referências consistentes sobre o comportamento na fase lag, porém o comportamento do $\mathrm{pH}$ observado neste período pode-se constatar que está ocorrendo mudanças na concentração de íons no meio de cultura. Um maior número de repetições destes pontos poderá esclarecer, sob ponto de vista estatístico, esta fase lag.

Os pontos referentes aos dias 9 a 15, já em triplicatas, representam um patamar. Isto é, depois de uma fase de crescimento exponencial ocorre a exaustão de um nutriente do substrato (ou aparece algum inibidor) e então a velocidade de crescimento cai para valores próximos de zero.

Elaborou-se a hipótese de que os ensaios relativos ao dia 9, 11, 13 e 15 são tratamentos equivalentes e não se pode afirmar que as médias obtidas sejam diferentes entre si. Para comprovar esta hipótese foi eleito o teste de Tukey, conforme proposto por Gomes (1963).

Uma das premissas adotadas antes da aplicação do teste de Tukey é que os ensaios comportaríam-se como experimentos totalmente casualizados, devido ao fato de terem sido realizados em laboratório em condições sempre muito uniformes.

Por problemas de contaminação microbiana foi perdida uma das repetições do ponto "dia 15" do ensaio, conforme consta na Tabela 9, da página 49. A aplicação do teste estatístico levou em consideração este caso. A Tabela 10., constante da página 53 , apresenta os valores dos dados dos ensaios referentes aos dias 9 a 15, em triplicatas, com exceção a uma delas: "dia 15", cujo ensaio foi perdido.

Para os quatro tratamentos o numero de graus de liberdade foi de 3 (4 - $1=$ 3). As 11 repetições dos ensaios implicaram em 10 graus de liberdade para o total, logo tem-se 7 graus de liberdade para o resíduo. A Tabela 11. apresenta a síntese da análise estatística, e é apresentada na página 53, logo em seguida da Tabela 10. 
Tabela 10. Ganho de peso da matéria seca (Peso da Matéria Seca Final - Peso da Matéria Seca Inicial) de explantes de nós epicórmicos de eucalipto, clone "H10", para os pontos referentes a "dia 9", "dia 11", "dia 13" e "dia 15" com as suas repetições disponíveis.

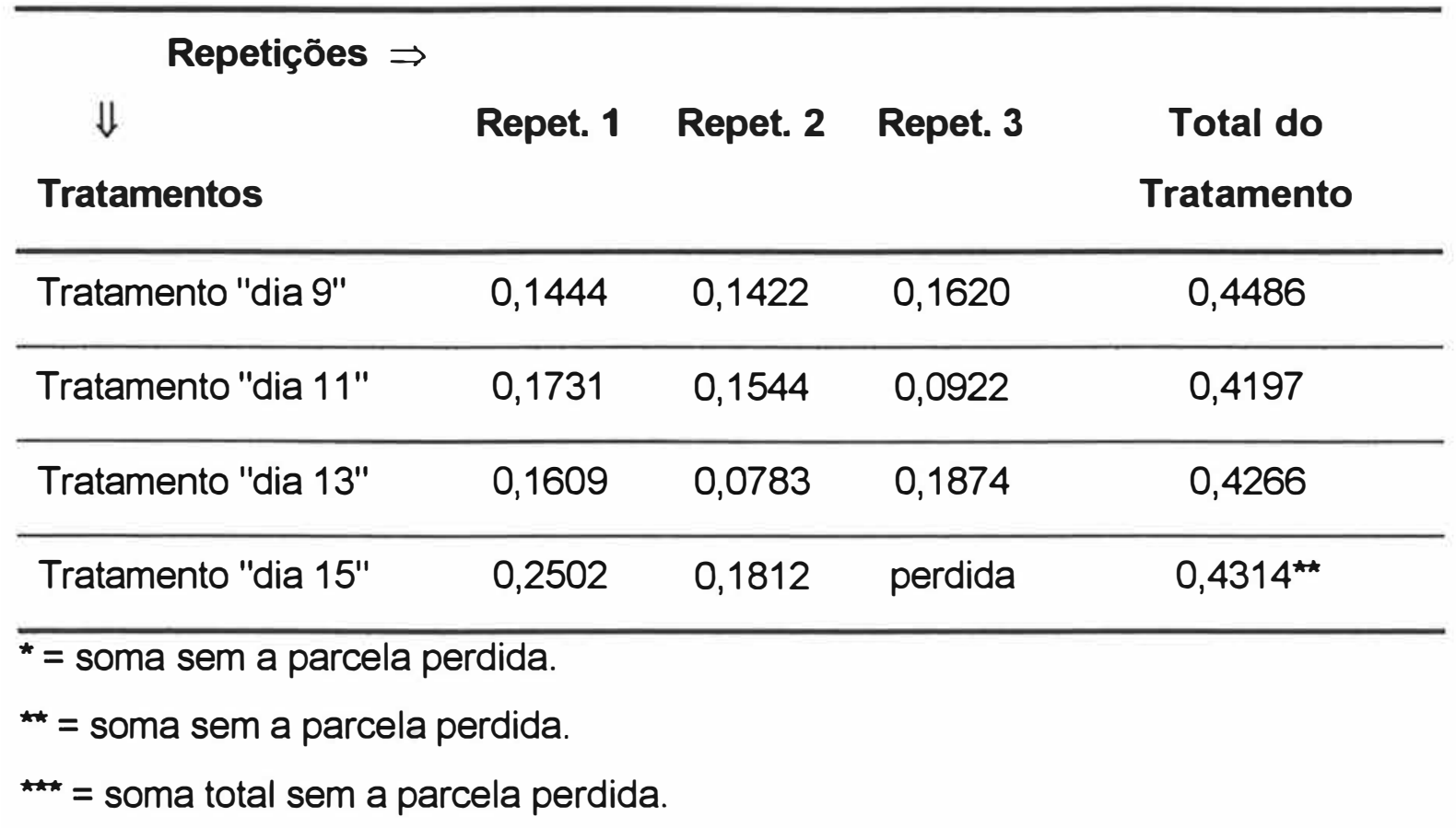

Tabela 11. Síntese da análise estatística referente aos dados da Tabela 10.

\begin{tabular}{lcccc}
\hline $\begin{array}{l}\text { Causa de } \\
\text { Variação }\end{array}$ & $\begin{array}{c}\text { Graus de } \\
\text { Liberdade }\end{array}$ & $\begin{array}{c}\text { Soma dos } \\
\text { Quadrados }\end{array}$ & $\begin{array}{c}\text { Quadrado } \\
\text { Médio }\end{array}$ & $\begin{array}{l}\text { Desvio } \\
\text { Padrão }\end{array}$ \\
\hline Tratamentos & 3 & 0,0086 & 0,0029 & 0,0539 \\
\hline Resíduo & 7 & 0,0127 & 0,0018 & 0,0424 \\
\hline Total & 10 & 0,0213 & 0,0021 & 0,1449 \\
\hline
\end{tabular}

$\mathrm{C}=2,9801 / 11=0,2709$ 
Para o teste Tukey será adotado o nível de $5 \%$ de probabilidade, então:

$$
\begin{aligned}
& \Delta=\mathrm{q}(\mathrm{s} / \sqrt{ } \mathrm{r}), \text { onde (Eq. } 7) \\
& \Delta=\text { intervalo de significância ao nivel de 5\%; } \\
& \mathrm{q}=\text { valor da amplitude total "estudentizada"; } \\
& \mathrm{s}=\text { desvio padrão residual; } \\
& \mathrm{r}=\text { número de repetições. }
\end{aligned}
$$

Aplicando os valores da Tabela 11. tem-se:

$$
\begin{aligned}
& \Delta=4,68(0,0424 / \sqrt{ } 3), \\
& \Delta=0,1146
\end{aligned}
$$

Tomando-se a maior e a menor média da Tabela 10., tem-se:

$$
\begin{aligned}
& \text { Maior média }=0,4486 / 2=0,2243 \\
& \text { Menor } \text { média }=0,4197 / 3=0,1399 \\
& \qquad \Delta^{\prime}=\text { Maior média }- \text { Menor média }=0,0844
\end{aligned}
$$

Como $\Delta^{\prime}<\Delta$, não pode-se afirmar que as médias são diferentes, logo é plausivel a hipótese de que os pontos referentes ao "dia 9" até o "dia 15" fazem parte de um patamar da curva de crescimento.

Os pontos referentes ao intervalo entre os dias 3 e 8 representam a fase exponencial de crescimento. Uma vez superada a fase de adaptação as células passam a crescer de forma muito rápida, porém não de forma indefinida. Acontecimentos como o final de algum nutriente, redução devida a mudanças químicas no meio, ou mesmo o surgimento de algum inibidor ou substância tóxica, podem levar a diminuição ou mesmo a paralisação do crescimento celular.

Durante a fase exponencial de crescimento, 0 incremento de massa dos explantes comportam-se matematicamente de acordo com a expressão:

$$
\begin{aligned}
& \mathrm{dX} / \mathrm{dt}=\mu \mathrm{X} \text {, onde } \\
& \mu=\text { velocidade específica de crescimento [ tempo }{ }^{-1} \text { ]; } \\
& X=\text { massa celular (peso da matéria seca) [gramas] }
\end{aligned}
$$


A integração da equação Eq. 8 permite calcular $o$ valor de $\mu$ através do coeficiente angular da reta relativa ao gráfico Ln (PSF-PSI) contra o tempo. Os dados da Tabela 9. relativos à coluna Ln(PSF-PSI) foram colocados na forma de gráfico (Figura 7), e os 5 pontos experimentais relativos ao intervalo entre o dia $3 \mathrm{e}$ o dia 8 foram submetidos a uma regressão linear obtendo-se os seguintes resultados:

$$
\operatorname{Ln}(\mathrm{PMSI}-\mathrm{PMSF})=-5,1363-0,4547 \Delta \mathrm{t}, \mathrm{com} r=+0,9900
$$

O ponto relativo ao dia 4 não foi considerado por estar claramente fora da curva de crescimento. Com mais repetições este ponto poderá ser então considerado.

$O$ valor de $\mu=0,4547$ dia $^{-1}$ significa uma taxa de crescimento de 454,7 miligrama de peso da matéria seca/grama de peso ao dia, ou então, 45,47\% em termos de peso da matéria seca ao dia. Comparando-se com os dados de Correia (1993), que trabalhando com meio bifásico, encontrou taxa de crescimento para clones de $E$. grandis de $21,9 \%$, pode-se afirmar que o sistema empregado possibilitou taxas de crescimento 2 vezes superiores.

Uma outra forma de explicitar a velocidade de crescimento de organismos vivos é a utilização da velocidade de duplicação $\left(t_{d}\right)$. Sob ponto de vista matemático a velocidade de duplicação é descrita como (Dias, 1982):

$$
\begin{aligned}
& t_{d}=\operatorname{Ln} 2 / \mu \text {, ou (Eq. 10) } \\
& t_{d}=0,6931 / 0,4547=1,5243 \text { dias ou 36,58 horas. }
\end{aligned}
$$

Ou seja, nas condições descritas neste trabalho, durante a fase exponencial na qual a velocidade de crescimento permanece constante, a cada 36,58 horas a massa seca dos explantes de eucalipto clone "H10" dobra.

O valor de velocidade específica de crescimento calculado entre os pontos "dia 3" e "dia 8" acima é o resultado de uma série de considerações matemáticas e 
fisiológicas, sem as quais o número obtido perde totalmente o seu significado. South (1991) analisando a utilização de um parâmetro similar (a velocidade específica de crescimento média), obtido por caminho muito semelhante ao utilizado para a determinação de $\mu$ neste trabalho, critica a inobservância, em várias referências bibliográficas, das considerações matemáticas nas quais determinado número foi obtido.

$\mathrm{Na}$ verdade a velocidade específica de crescimento é um parâmetro dependente de vários outros, devendo ser utilizado sempre dentro de um cenário onde sejam consideradas as suas condicionantes.

Vários fatores podem afetar a velocidade específica de crescimento. Primeiramente, deve-se analisar que o mesmo foi obtido pela integração de uma curva, portanto influenciada pela qualidade dos dados utilizados para a construção da curva. Foi demonstrado anteriormente que existe um erro associado a medida de massa dos explantes. Dias (1982) relatou que erros relativos a medida da massa celular de 3 a $8 \%$ podem implicar em desvios no cálculo de $\mu$, dependendo do valor deste, de 5 a $13 \%$.

A temperatura é outro fator que pode influenciar a determinação da velocidade específica de crescimento. É comum, segundo Dias (1982), que a influência da temperatura sobre $\mu$ seja determinada por uma curva do tipo de Arrhenius:

$$
\begin{aligned}
& \mu=\mu_{T} e^{(- \text {Ea/RTa })}, \text { onde } \quad \text { (Eq. 11) } \\
& \mu=\text { velocidade específica de crescimento; } \\
& \mu_{T}=\text { velocidade específica de crescimento a uma dada }
\end{aligned}
$$

temperatura;

$$
\begin{aligned}
& E_{a}=\text { Energia de ativação; } \\
& R=\text { Constante; } \\
& T_{a}=\text { Temperatura de Ativação. }
\end{aligned}
$$

No âmbito deste trabalho buscou-se manter a temperatura o mais fixa 
possivel. Os ensaios foram realizados em sala de crescimento climatizada, mas devido a potência luminosa instalada (cerca de 1.700 watts de lâmpadas florescentes) havia uma variação entre o período de luz e o período de escuro. Como relatado anteriormente a variação ficou em $\pm 4{ }^{\circ} \mathrm{C}$ medida com termômetro de máxima e mínima, o suficiente para causar alguma variação nas medidas de $\mu$.

Mais importante do que a temperatura, seguramente é a influência da concentração do meio de cultura. Esta é dada pela equação de Monod, descrita por Gaudy Junior \& Gaudy (1981) como uma curva assintótica e já anteriormente descrita neste trabalho pela equação Eq. 3:

$$
\mu=\mu_{\max } S_{o} /\left(K_{s}+S_{0}\right), \text { em que, }
$$

Para microorganismos a equação de Monod tem como substrato limitante a fonte de carbono. No caso específico do cultivo de explantes de eucalipto, possivelmente o substrato limitante seja outro, uma vez que a concentração de açúcar é extremamente elevada em relação aos demais nutrientes minerais. A indisponibilidade no momento de dados nutricionais impossibilita uma discussão mais detalhada sobre a influência do substrato sobre a velocidade específica de crescimento.

A variação do $\mathrm{pH}$ fornece indício interessante de que possa estar havendo rápido consumo de algum nutriente mineral. Observando-se a Figura 6 , pode-se notar que o pH sofre uma queda acentuada no processo de autoclavagem. Do valor de 6,0 \pm 0,1 no momento do preparo, após a esterilização, cai para 5,3 (valor confirmado em 4 repetições). Leifert et al. (1991) apontam a baixa capacidade de tamponamento dos meios de cultura utilizados para o crescimento de plantas como o responsável pela variação do $\mathrm{pH}$. Citando experimento com meio de cultura sólido para Hemerocallis sp. (Stella d'ora) em que o pH logo após a esterilização foi medido em 5,7 , estes autores observaram que mesmo na ausência de plantas, bem como de qualquer microorganismo, houve uma queda do $\mathrm{pH}$ até o valor 5,0 . 
Durante os ensaios ocorreu uma queda do pH de 5,7 inicial até 4,0 em cinco dias, depois os valores deste parâmetro foram subindo até estabilizarem em tomo de 4,7. A variação do $\mathrm{pH}$ no meio de cultura pode ser observada no cultivo de explantes obtidos de nós epicórmicos de eucalipto.

$\mathrm{O} \mathrm{pH}$ inicial de 5,3 subiu rapidamente para 5,8 nas primeiro 24 horas de cultivo, para iniciar um lento decréscimo até o valor 5,4 (quinto dia) em que permaneceu por seis dias até começar novamente a subir até o valor de 5,8 no décimo quinto dia de cultivo.

Através dos dados constantes da Tabela 9 é possível propor um modelo de crescimento de tufos de eucalipto "in vitro". O ajuste feito com o modelo computacional proposto por Zullo Júnior \& Arruda (1986) e a equação do tipo polinomial de terceira ordem:

$$
(P S F-P S I)=0,0052 e^{(0,8406-0,0717 \times 2+0,0021 \times 3)},
$$

com $n$ (número de pontos do ajuste) $=18$, e $r=+0,9266$.

Curvas deste tipo propiciam a derivação do tipo:

$$
\mu=b_{1}+1 b_{2} t+3 b_{3} t^{2}
$$

porém não existe correlação biológica entre os coeficientes "b". Segundo Hunt (1991) este tipo de curva é utilizado mais como uma aproximação estatística de uma curva logística do que uma representação de fenômeno biológico propriamente dito. No entanto, este mesmo autor cita 43 referências bibliográficas que se utilizam deste tipo de função para descrever modelos de crescimento de plantas. 


\section{CONCLUSÕES.}

Baseado nos dados apresentados neste texto é possivel se chegar as seguintes conclusões:

1. O protocolo proposto para a padronização dos explantes mostrouse adequado com relação a padronização em relação ao peso fresco dos explantes onde obteve-se um coeficiente de variação (CV\%) de 4,18\%;

2. Existe uma correlação positiva entre o peso seco dos explantes e o peso fresco. Esta correlação é expressa pela equação Peso Seco $=0,125+0,0751$ Peso Fresco, com o coeficiente de correlação de + 0,9080;

3. Com a metodologia utilizada foi possivel calcular a velocidade específica de crescimento tufos de eucalipto "in vitro". O valor obtido foi de $\mu=$ $0,4547 \mathrm{dia}^{-1}$, correspondente a um tempo de duplicação de 36,59 horas.

4. Os dados obtidos permitem que se proponha uma metodologia para determinação da velocidade de crescimento de explantes. 


\section{REFERÊNCIAS BIBLIOGRÁFICAS}

ALVARD, D.; TEISSON, C.; COTE, F. Comparison of methods of liquid medium culture for banana micropropagation. Effects of temporary immersion of explants. Plant Cell Tiss. Org. Cult., v. 32, p. 55-60. 1993.

ANDRADE, E. N. O Eucalipto. 1a. Ed. Jundiaí: Companhia Paulista de Estrada de Ferro. 1939. Volume único.

BAGNI, N.; CORSINI, E.; SERAFINI FRACASSINI, D. Growth-Factors and Nucleic Acid Synthesis in Helianthus tuberosus. I. Reversal of Actinomicin D Inhibition by Spermidine. Physiol. Plant., v. 24, p. 112-117, 1971.

BERTOLUCCI, F. de L. G., e PENCHEL, R. M. Clonagem do Eucalipto: efeitos sobre a produtividade e qualidade da madeira. Ciência Hoje/Suplemento. v. 16, n. 91, p. 16-21, 1993.

BORZANI, W. Cinética de Processos Fermentativos. In: BORZANI, W.; ALMEIDA LIMA, U. de; AQUARONE, E. (Ed.) Biotecnologia - Engenharia Bioquímica. São Paulo: EDUSP/Ed. Edgard Blücher. 1975. v. 3, p. 168-184: Cinética de Processos Fermentativos. 
CALDAS, L. S.; HARIDASAN, P.; FERREIRA, M. E. Meios nutritivos. In: TORRES, A. C.; CALDAS, L. S. Técnicas e Aplicações da Cultura de Tecidos de Plantas. Brasília: ABCTP/EMBRAPA-CNPH, 1990, p. 37-70: Meios nutritivos.

CARNEIRO, V. T. DE C.; CONROI, T. Protoplastos de Células Vegetais. In: TORRES, A. C.; CALDAS, L. S. Técnicas e Aplicações da Cultura de Tecidos de Plantas. Brasília: ABCTP/ EMBRAPA-CNPH, 1990, p. 171-202: Protoplastos de Células Vegetais.

CASTRO, P. R. C. Importância das relações fonte-dreno na produtividade. In: REUNIÃO BRASILEIRA DE FISIOLOGIA VEGETAL, 2a., Piracicaba, 1989. Anais da Segunda Reunião Brasileira de Fisiologia Vegetal. Piracicaba: Sociedade Brasileira de Fisiologia Vegetal, 1989, p. 135-145.

CAUSTON, D. R.; VENUS, J. C. The Biometry of Plant Growth. Londres: Edward Amold, 1981, p. 309.

CHEN, Z; SONG, Y.; LI, W. Cell Suspension Culture and Mutant Screening in Perennial Crops. In: CHEN, Z.; EVANS, D. A.; SHARP, W. R.; AMMIRATO. V.; SÖNDAHL, M. R., Handbook of Plant Cell Culture: Perennial Crops. New York: Macmillan Publishing Co., 1990, v. 6, p. 76-91: Cell Suspension Culture and Mutant Screening in Perennial Crops.

CONNELL, J.H.; SLATYER, R. O. Mechanisms of succession in natural communities and their role in community stability and organization. The American Naturalist, v. 111. n. 982, p. 1119-1114, nov./dez., 1977. 
CORREIA, D. Crescimento e desenvolvimento de gemas na multiplicação de Eucalyptus spp. "in vitro" em meio de cultura líquido e sólido. Piracicaba, 1993. 113 p. Tese (Mestrado) - Escola Superior de Agricultura "Luiz de Queiroz", Universidade de São Paulo.

COUTO, H. T. Z. Comunicação pessoal ao autor, 1995.

DEBERGH, P. C. Evolution and automation in micropropagation and artificial seeds production. In: TERZI, M.; CELLA, R.; FAVAVIGNA, A. Current Issues in Plant Molecular and Cellular Biology: Proceedings of the VIIlth Intemational Congress on Plant Tissue and Cell Culture, Florence, Italy, 12-17 June, 1994. Dordrecht: Kluwer Academic Publishers, 1995, p .95-104: Evolution and automation in micropropagation and artificial seeds production.

DIAS, J. M. C. DE S. Aplicação do método dinâmico de medida da velocidade específica máxima de crescimento celular à fermentação alcoólica contínua de mosto de melaço. São Paulo, 1982. 225 p. Tese (Mestrado) - Escola Politécnica da Universidade São Paulo.

DOLEY, D. Effects of Shade on Gas Exchange and Growth in Seedlings of Eucalyptus grandis Hill ex Maiden. Aust. J. Plant Physiol., v. 5, p. 723-738, 1978.

ESCALANT, J. V.; TEISSON, C.; COTE, F. Amplified somatic embryogenesis from male flowers of triploid banana (Musa spp.). In vitro Cell. Dev. Biol. v. 30, p. 181-186, outubro, 1994.

FAHN, A. Anatomia Vegetal. Madri: Ediciones Pirámide, S. A.,1982 . 599 p. 
GASPAR, Th.; KEVERS, C.; DEBERGH, P.; MAENE, L.; PAQUES, M.; BOXUS, Ph. Vitrification: morphological, physiological and ecological aspects. In: BONGA, J. M.; DURZAN, D. J. Cell and Tissue Culture in Forestry: General Principles and Biotechnology. Dordrecht: Martinus Nijhoff Publushers, 1982 (Vol. 1) p. 152-166: Vitrification: morphological, physiological and ecological aspects.

GAUDY JUNIOR, A. F. \& GAUDY, E. T. Microbiology for environmental scientists and engineers. Tokyo: McGraw-Hill International Book Company, 1981 p. 207-305.

GEPS, P. Characterizing Plant Phenology: Growth and Development Scales. In: WISIOL, K; HESKETH, J. D. Plant Growth Modeling for Resource Management. Vol II, Quantifying Plant Process. New York: CRC Press, 1987. p. 3-24.

GOMES, F. P. Curso experimental de estatistica. 2a. ed. Piracicaba: ESALQ/USP. 1963. $384 p$.

GONÇALVES, A. N. The growth and developmental physiology of Eucalyptus in cell and tissue culture systems. Columbus, 1975. $210 \mathrm{p}$. Thesis (Master of Science) - The Ohio State University.

GONÇALVES, A. N. Reversão à juvenilidade e clonagem de Eucalyptus urophylla, S. T. Blake "in vitro". Piracicaba, 1982. 97 p. Tese (Doutorado) - Escola Superior de Agricultura "Luiz de Queiroz", Universidade de São Paulo.

GRIME, J.P. Vegetation classification by reference to strategies. Nature, v. 250, p. 26-31, julho. 1974. 
GRIME, J.P. Evidence for the existence of three primary strategies in plant and its relevance to ecological and evolutionary theory. The American Naturalist, v. 111, n. 982, p. 1169-1194, nov./dez. 1977.

HANGARTER, R. P.; STASINOPOULOS, T. C. Effect of Fe-Catalyzed Photooxidation of EDTA on Root Growth in Plant Culture Media. Physiol. Plant., v. 96, p. 843-847. 1991.

HUNT, R. Plant Growth Curves. The Functional Approach to Plant Growth Analysis. London: Edward Arnold (Publisher) Ltda. 1982. 248 p.

INGESTAD, T. A Definition of Optimum Nutrient Requirements in Birch Seedling. I. Physiol. Plant., v. 23, p. 1127-1138, 1970.

INGESTAD, T. A Definition of Optimum Nutrient Requirements in Birch Seedling. II. Physiol. Plant., v. 24, p.118-125, 1971.

INGESTAD, T. Nitrogen Stress in Birch Seedling. II.N, K, P, Ca, and Mg Nutrition. Physiol. Plant., v. 45, p.149-157, 1979.

INGESTAD, T.; AGREN, G. I. Theories and methods on plant nutrition and growth. Physiol. Plant., v. 84, p.177-184, 1992.

JANZEN, D. H. Ecologia Vegetal nos Trópicos.. São Paulo: Temas de Biologia, vol. 7. E. P. U./EDUSP. 1980, 78 p. 
LAWLOR, D. W. Concepts of nutrition in relation to cellular process and environment. In: PORTER, J. R.; LAWLOR, D. W. ed. PLANT GROWTH: interactions with nutrition and environment. Cambridge: Cambridge University Press, 1991. p. 1-32. (Seminar Series of Society for Experimental Botany, \#43): Concepts of nutrition in relation to cellular process and environment.

LEIFERT, C.; MURPHY, K. P.; LUMSDEN, P. J. Mineral and carbohydrate nutrition of plant cell and tissue cultures. New York: CRC Critical Reviews in Plant Science, 74 p. 1995.

MARGARA, J. Multiplicacion Vegetativa y Cultivo in Vitro. Los Meristemos y la Organogénesis. Madri: Ediciones Mundi-Prensa.1989. 232 p.

MEZZETTI, B.; ROSATI, P.; CASALICCHIO, G. Actinidia deliciosa C. F. Liang in vitro. I. Growth and mineral uptake by explants. Plant Cell Tiss. Org. Cult., v. 25, p. 91-98, 1991.

SOARES, L. F. G. Modelagem e Simulação Discreta de Sistemas. Rio de Janeiro: Editora Campus. 1992. 250 p.

SOUTH, D. B. Testing the hypothesis that mean relative growth rates eliminate size-related growth differences in tree seedlings. New Zealand of Forestry Science, v. 21, n. 2/3, p. 144-164, 1991.

TAIZ, L.; ZEIGER, E. Plant Physiology. Redwood City, California: The Benjamin/ Cummings Publishing Company, Inc., 1991. Growth and Development: The cellular basis of growth and morphogenesis, p. 371-397. 
TEISSON, C.; COTE, F. A new concept of plant in vitro cultivation liquid medium: temporary immersion. In: TERZI, M.; CELLA, R; FAVAVIGNA, A. Current Issues in Plant Molecular and Cellular Biology: Proceedings of the VIIlth International Congress on Plant Tissue and Cell Culture, Florence, Italy, 1217 June, 1994. Dordrecht: Kluwer Academic Publishers, 1995, p .105-110: A new concept of plant in vitro cultivation liquid medium: temporary immersion.

TREWAVAS, A.; ALLAN, E. An Assessment of the Contribution of Growth Substances to Plant Development. In: WISIOL, K. \& HESKETH, J. D. New York: CRC Press, 1987. p. 25-48: An Assessment of the Contribution of Growth Substances to Plant Development.

ZULLO JÚNIOR, J.; ARRUDA, F. B. Programa computacional para ajuste de equações em dados experimentais. Campinas: Instituto Agronômico, 1986. 23 p. (Boletim Técnico no. 113). 